\title{
3 Research Square

\section{De novo characterization of the Camellia sinensis transcriptome and comprehensive analysis of the diploid and triploid leaf morphology and physiological differences}

\author{
Yong QI \\ Guizhou University \\ Xinzhuan YAO \\ Guizhou University \\ Degang ZHAO \\ Guizhou University \\ Litang Lu ( $\nabla$ ltlv@gzu.edu.cn ) \\ Guizhou University https://orcid.org/0000-0003-4880-8538
}

Research article

Keywords: Camellia sinensis; diploid; triploid; transcriptome sequencing; stomatal

Posted Date: October 23rd, 2019

DOl: https://doi.org/10.21203/rs.2.16365/v1

License: (c) (i) This work is licensed under a Creative Commons Attribution 4.0 International License.

Read Full License 


\section{Abstract}

Background Polyploidization has undergone a series of significant changes in the morphology and physiology of tea plants as plants multiply, especially in terms of increased growth rate and genetic gainsResult In this study, we found that the leaves of triploid tea had obvious growth advantages compared with diploid tea leaves, which was $59.81 \%$ higher than that of diploid leaves areas. The morphological structure of the triploid leaves showed obvious changes, the xylem of the veins was more developed, the cell-to-cell gap between the palisade tissue and the sponge tissue became larger, and the stomata of the triploid leaves were enlarged. After the polyploidy of tea, the content of secondary metabolites in tea leaves also changed significantly. Transcriptome sequencing analysis showed that after the triploidization of tea, the changes of leaf morphology and physiological characteristics were affected by the specific expression of some key regulatory genes. we identified a large number of transcripts and genes that might play important roles in leaf development, especially those involved in cell division, photosynthesis, hormone synthesis, and stomatal development.Conclusion This study will improve our understanding of the molecular mechanisms of tea leaf and stomatal development and provide the basis for molecular breeding of high quality and yield tea varieties. Furthermore, it gives information that may enhance understanding of triploid physiology.

\section{Background}

Polyploid refers to the number of complete genomes in somatic cells reaching three or more. Polyploidy rarely occurs in the animal kingdom, but is widespread in the plant kingdom. Polyploidization usually leads to lethal effects in animals, but it is beneficial for plants to be polyploidized. Plant chromosome polyploidization can promote the evolution of biological groups, facilitate the preservation of species and enhance the adaptability of species. It is one of the most important ways of evolutionary variation of plants in nature. About $80 \%$ of existing plants have undergone one or more polyploidization events in evolutionary history [1-3]. During plant evolution, polyploidization increases plant genome and gene dose, which provides ample space and possibilities for the formation of new species [4,5]. Karyoplasmicratio is usually fixed in eukaryotes. Therefore, the increase of genetic material in the nucleus often causes changes in cell size [6,7]. Generally, as the ploidy of the genome increases, the volume of plant cells and nuclei becomes correspondingly larger, and the leaf growth morphology index, pollen, fruit, seed size and stem diameter increase accordingly, and the characteristics of this polyploid are called great $[8,9]$. In the epidermal cells of Arabidopsis thaliana, the size of epidermal cells and the DNA content in the nucleus are proportional to each other. The DNA content is multiplied from $4 \mathrm{C}$, and the corresponding Arabidopsis thaliana cell volume is also increased [8].

Plant polyploidization has certain effects on physiology and development, including water balance, photosynthetic rate, carbon dioxide exchange rate, hormone levels and gene activation $[10,11]$. In theory, an increase in plant polyploid genomics results in longer periods of cell division, leading to longer cell division, slower, and slower physiological processes in many plants [12]. However, Well found that hexaploid wheat has stronger metabolism and growth rate than tetraploid wheat, and root growth, 
mitosis and biomass storage of hexaploid wheat are more rapid than tetraploid [13]. The doubling of chromosomes first causes a series of changes in the plant genome, which in turn affects the growth and development system of plants [14]. The release of the whole genome by polyploid plants causes changes in genomic structure, resulting in re-regulation of gene expression and changes in gene expression levels. A large amount of research work has shown that plant polyploidization causes changes in genome interactions, DNA sequences and gene expression. This change is called genome shock [15]. Kashkrush used CDNA-APLP technology to determine the expression levels of allopolyploid and natural polyploid genes in Arabidopsis, cotton and wheat [16]. Studies have shown that the gene expression levels of different ploidy plants vary with the growth and development of organs of plants.

Current research indicates that polyploidization of plants can indeed alter the physiological activities and developmental processes of plants. However, the research results have their own advantages. With the deepening of research, the general pattern of multiplication of plant growth and physiological metabolism will gradually become clear. Here, we discuss how alteration of the different Chromosome ploidy can affect the final leaf size and describe genes and networks involved in each of these processes. The molecular mechanism of the growth and development of diploid and triploid leaves of tea trees can reveal the changes in molecular level during the growth and development of leaves and the regulation of key genes, and enrich the theoretical basis of molecular biology of plant organs. On the other hand, the study of the molecular mechanism of its leaf growth and development can provide a theoretical basis for its molecular breeding, breeding excellent new varieties and solving practical problems in production.

\section{Results}

\section{Morphological characteristics of diploid and triploid tea leaves}

The leaf phenotypes of diploid and triploid annual shoots were determined under field growth conditions. As shown in Fig.1, the leaves of triploid tea trees have obvious growth advantages compared with diploid tea leaves, and the leaf length, leaf width and leaf area are larger than those of diploid leaves. Compared with diploid leaf length, leaf width and leaf area, they increased by $23.37 \%, 41.12 \%$ and $59.81 \%$, respectively, with extremely significant differences. However, the diploid leaf thickness was significantly higher than that of the triploid leaf, which was $295.63 \mu \mathrm{m}$ and $252.33 \mu \mathrm{m}$, respectively, and the difference was extremely significant. There was no significant difference in the length of the petiole of triploid and diploid tea, which were $0.7 \mathrm{~cm}$ and $0.667 \mathrm{~cm}$, respectively. The diameter of the petiole of the triploid tea is larger than the diameter of the diploid petiole, with significant differences, $2.05 \mathrm{~mm}$ and $2.31 \mathrm{~mm}$, respectively. The dry weight of the three-leaf leaves increased by $39.29 \%$ compared with the diploid, and the difference was extremely significant (Table 1 ).

\section{Analysis of the number and size of stomata in diploid and triploid leaves}

In order to investigate the difference in stomatal appearance on the epidermis of diploid and triploid tea leaves, we performed a statistical analysis of the size and density of the stomata of the epidermis in the same part of the tea leaves. The results showed that the stomata size (length and width) of triploid 
leaves were significantly larger than diploid, which increased by $57.20 \%$ and $84.44 \%$, respectively, compared with diploid length and width. However, the stomata density of triploid leaves is significantly lower than that of diploids, and the stomata density of diploid tea leaves is twice that of triploid stomata (Fig. 2).

\section{Paraffin section analysis of diploid and triploid leaves}

In order to understand the difference in growth and development of diploid and triploid leaves, we observed paraffin sections. As a result, it can be seen from Fig. 3 that the leaf vein portion of the diploid tea tree undergoes a significant change after triploidization. Among them, the xylem of the veins is the most obvious. The xylem of the triploid vein is more developed than the diploid, and the area is also larger. The area of the triploid xylem is three times that of the diploid, which is $0.476 \mathrm{~mm}^{2}$. The increase in the area of the triploid xylem is caused by two reasons: one is the increase in cell areas; the other is the increase in the number of xylem cells, and the number of diploid and triploid xylem cell layers averaged 19 and 25 . The number of triploid xylem cell layers increased by $30.67 \%$ compared to diploid. There were no significant changes in the size of the diploid and triploid veins and the phloem and formation.

It can be seen from Fig. 4 that the shape and size of the diploid and triploid mesophyll cells are significantly different, and the epidermal cell thickness of the triploid mesophyll is $22.28 \%$ larger than that of the diploid, which is extremely significant. The cells of the leaf bark of diploid tea leaves are arranged closely, and the shape and size are relatively uniform. The cells of the triploid leaf mesophyll puncture are loosely arranged, the cell gap is large, and the cell shape and size are different. The average length of the diploid palisade tissue cells is larger than that of the triploid, and the length is $65 \mu \mathrm{m}$, which is $15.65 \%$ longer than the triploid. The width of the triploid palisade tissue cells was significantly larger than that of the diploid, which was $70 \%$ higher than that of the diploid. Diploid sponge tissue cells are small and dense, and the number is more than that of triploids, which is about twice the number of triploid cells.

\section{Illumina sequencing and reads assembly}

To investigate the molecular mechanisms of diploid and triploid leaf growth, and to understand the metabolic processes involved in leaf growth and development, we analyzed the gene expression profiles of diploid and triploid leaves. By de novo transcriptome sequencing, the test samples obtained an average of about 40 million original reads, with high quality reads reaching over $99 \%$, six cDNA libraries (CaS419_1, CaS419_2, CaS419_3, CaS4_1, CaS4_2, and CaS4_3) were generated from diploid and triploid mRNAs, which were sequenced using Illumina deep-sequencing HiSeq ${ }^{\text {TM }} 2000$.

The raw data obtained after sequencing on the machine is filtered, the sequencing error rate is checked, the GC content distribution is checked, and the GC content analysis is used to detect whether there is $A / T$ or $\mathrm{G} / \mathrm{C}$ separation phenomenon. Finally, 6 sample data (clean read) for subsequent analysis were obtained. The filtered data is summarized in the table below. Among all the raw reads, $96 \%$ had Phredlike quality scores at the Q20 level (an error probability of $1 \%$ ).After removing adapters, low-quality sequences and ambiguous reads, we obtained approximately 45 million, 43 million, 60 million,58 million 
,62 million and 48 million clean reads from the diploid samples (CaS419_1, CaS419_2, and CaS419_3, ), and triploid samples (CaS4_1 , CaS4_2, and CaS4_3), respectively (Table 2). Raw reads are filtered and assembled by De novo assembly software Trinity. The assembled sequences are redundant and spliced by software TGICL to obtain the longest non-redundant unigene set and further statistics on unigene sets.

\section{Functional annotation and Cluster Analysis}

Due to the lack of a complete genome sequence in Camellia sinensis, only 27,031 unigenes were coannotated into six databases (NR, NT, SwissProt, COG, GO, and KEGG), accounting for $26.13 \%$ of 103,448 unigenes. Among them, the most frequently cited genes in the NCBI NR and NT databases were 90,547 and 89,933 unigenes ( $87.53 \%$ and $86.93 \%$ of all annotated unigenes), while $35,298(34.12 \%)$ and 61,318 $(59.27 \%)$ unigenes could be annotated into the COG, Swiss-Prot database. We annotated $45,820(44.29 \%)$ and 67.980 (65.71\%) unigenes to GO and KEGG databases (Fig. 5).

The main GO terms included biological process (BP), cellular component (CC), and molecular function (MF). Based on sequence homology, 45,820 unigenes were mainly categorized into 55 functional groups (Fig. 6). In the category of BP, the two major groups of cellular processes and metabolic processes accounted for the highest proportion. Of these, approximately 24,750 genes have been annotated as metabolic process categories, which may allow the identification of novel genes involved in secondary metabolism pathways in triploid. As for the MF category, unigenes with binding and catalytic activity formed the largest groups. For CC, the top three largest categories were cell, cell part, and membrane. To further evaluate the reliability of our transcriptome results and the effectiveness of our annotation process, we searched the annotated sequences for genes with COG classifications (Fig. 7). Among the 26 COG categories, the cluster for "General function prediction only" $(9,286)$ represented the largest group, followed by "Transcription" $(5,108)$, "Posttranslational modification, protein turnover, chaperones" $(4,438)$, and "Replication, recombination and repair" $(4,369)$. The categories "Extracellular structures" (6) was the smallest group.

To analyze of the biological functions of the unigenes, we used the annotated sequences to comparisons against the KEGG database. In total, 67,980 annotated unigenes were assigned to 136 known pathways based on the KEGG BLAST analysis. The top 19 pathways with the largest numbers of unigenes are listed in Fig. 8. The majority of the unigenes $(22,658 ; 31.95 \%)$ were involved in Global and overview maps pathways, followed by pathways in Carbohydrate metabolism (7,072 unigenes; $9.97 \%)$, Translation $(6,418$ unigenes; $9.05 \%$ ), and Folding, sorting and degradation (4,408 unigenes; $6.22 \%$ ).

\section{Differentially Expressed Genes and qRT-PCR Validation Between Diploid and Triploid Camellia sinensis}

To confirm the results of the Solexa/Illumina sequencing, twelve unigenes were selected for quantitative RT-PCR assays. The qRT-PCR analysis performed for ten upregulated and two downregulated DEGs growth-related genes confirmed the transcriptomic changes detected by RNA-seq (Fig. 9). Although the expression levels did not exactly match; however, Quantitative real-time PCR analysis showed that the 
patterns of gene expression were consistent with RNA-seq results. Thus, qRT-PCR results validated the reliability of RNA-seq data.

\section{Analysis of key gene expression of stomatal development based on transcriptome results}

In order to analyze the difference in stomatal development of the diploid and triploid leaves of tea plants, We identified 16 differentially expressed stomatal-related genes $(P<0.005)$, differences in expression of these genes lead to changes in triploid stomatal density and size. Nine genes belong to the Negativeregulatory factors, which are key regulators of stomatal in plants. In the negative regulatory family, SDD1, SERK1,2 and EPF1,2 have a negative regulatory effect on stomatal development, whileEPLF9/ stomagenhas a positive regulatory effect. Among them, the SDD1 and SERK1 genes are up-regulated and the EPF1 gene is down-regulated (Table 3). SERKS can interact with TMM in a non-ligand-dependent manner to form a multiprotein receptor complex and negatively regulate stomatal development through signal transduction. These genes are involved in biosynthesis and signal transduction of stomatal development by participating in different biological processes. For example, During stomatal development, cysteine-rich secretory peptides belonging to the EPF/EPFL family act as ligands to interact with the corresponding receptors to transmit developmental signals, ensuring proper stomatal density and distribution. The key transcription factor involved in stomatal development in plants is the $b H L H$ type protein, which Family SPCH, FAMA and MUTE play important regulatory roles in stomatal development. There was no significant difference in expression between these three transcription factors in diploid and triploid.

The $\mathrm{COP}$ and $\mathrm{HIC}$ genes are stomatal development factors that respond to light and $\mathrm{CO}_{2}$ signaling, in which the COP gene is down-regulated and $H I C$ is up-regulated.

\section{Identification and expression analysis of candidate genes involved in leaves development based on transcriptome results}

The morphological structure of the leaves seems simple, but the regulation mechanism of its development is very complicated. The final size of leaves, is tightly controlled by environmental and genetic factors that must spatially and temporally coordinate cell expansion and cell cycle activity. In this study, we identified 28 putative genes associated with leaf development that belong to different pathways, including cell division, photosynthesis, transcription factor, and auxin synthesis, which showed significant differential expression between diploid and triploid.

Transcripts involved in Photosynthesis-photoreaction phase were observed to be differentially expressed, including genes encoding Photosystem I (PS $₫)$, photosystem II (PS $\otimes)$, cytochrome b6/f complex, and ATP synthase. The center action of PS I is the pigment molecule P700, while Psa $A$ and Psa $B$ are key genes regulating the synthesis of $\mathrm{P} 700$ chlorophyll a apolipoprotein $\mathrm{A} 1$ and $\mathrm{A} 2$. The photoreaction center pigment of PSII is $\mathrm{P} 680$, and the $P s b A$ and $P s b E$ genes are involved in the synthesis of the P680 reaction center D1 protein. PetB is a key gene involved in the synthesis of the cytochrome b6 $\mathrm{f}$ complex. F1B is a Ftype $\mathrm{H}+$ transport ATPase subunit $\beta$ gene in ATP synthase. All these genes were down-regulated in leaves 
and are functional essential for carbon dioxide assimilation. Interestingly, it is contrary to the photoreaction phase of photosynthesis gene expression, all of the key enzymes in the carbon reaction phase is up-regulated. Among them, ribulose-1,5-bisphosphate carboxylase/oxygenase Rubisco gene, phosphoenolpyruvate carboxylase $P P C$ and malate dehydrogenase $M D H 1$ were significantly up-regulated (Table S1).

To explore the intracellular transcriptional activity of diploid and triploid plants, we analyzed the expression of genes involved in the regulation of RNA polymerase and transcription initiation factors during transcription. The results showed that RNA polymerase I, RNA polymerase II and transcription initiation factor were both up-regulated. The RPB2 gene and the TFIIA1 gene regulating RNA polymerase II and transcription initiation factor were significantly up-regulated, which was up-regulated by about 2.5fold compared to diploid (Table 4).

The expression of cell cycle-associated genes that regulate cell division can alter the organ volume of a plant, showing an increase in the number of cells and expansion of the cell volume in time and space. Cyclin-dependent kinase $(C D K)$, also known as the cell cycle engine molecule, plays a central role in the regulation of cell cycle function. The cyclin-dependent kinase 1 (CDK1) gene is up-regulated 6-fold compared to the diploid (Table 4). The CDK1 gene plays a key role in controlling the eukaryotic cell cycle by regulating centrosome circulation and mitosis initiation, promoting G2-M conversion, and regulating G1 and G1-S transformation by binding to multiple interphase cyclins. Cyclin-dependent kinase 7, CDK7, is a catalytic subunit of the $C D K$-activated kinase $(C A K)$ complex that regulates cell cycle progression. The relative diploid expression of $C D K 7$ gene was up-regulated by $22.66 \%$ in triploid leaves of tea (Table 5). The serine/threonine kinase BUB1 gene is involved in cell cycle control and RNA polymerase IImediated RNA transcription, and is also up-regulated in triploids, which is about twice the expression of diploid genes.

Taken together, these results provide a framework for the regulatory network of leaf development response in diploid and triploid.

\section{Discussion}

\section{Analysis of molecular mechanism difference between diploid and triploid leaf development}

Plant polyploid cells have additional genomic genetic material, and the ratio of nuclear genetic material to cell size in eukaryotes, ie karyoplasmicratio, is usually fixed in eukaryotes [17,18], so the increase of genetic material in the nucleus usually causes the change of cell size. After plant polyploidization, the plant tissues and organs are correspondingly larger, and the leaf growth morphology index, pollen size, seed size and stem diameter of the plants are correspondingly increased. The characteristics of this polyploid are called giant. The enormousity of the polyploid organs leads to growth advantages, Under the same growth conditions, the height and breast diameter of the hybrid triploid Populus tomentosa B301 cultivated by Zhu were significantly higher than those of the diploid [19]. The homologous triploid tea tree 'QianFu 4' leaves selected in this study were significantly larger than the diploid tea leaves. The 
increase of plant organs is generally caused by an increase in the number of cells or expansion of cell volume. Previous studies have found that an increase in plant cell ploidy does contribute to an increase in cell volume $[8,9]$.

In the observation of paraffin sections of diploid and triploid tea leaves, we found that the xylem cells in the veins of the leaves of triploid tea trees are larger than diploids, and the number of xylem cells is more. triploid palisade tissue and sponge shape and size of the tissue cells in the same part of the leaves changed significantly. The cells of the triploid palisade tissue and sponge tissue became bigger, and the cell-to-cell gaps expanded. The size of the final leaves of a plant is determined by cell division, differentiation, and expansion. The number of cells that will be produced during the cell division phase of plant leaf development will determine the final leaf size. In most cases, there is a direct correlation between cell number and organ size. [20]. Therefore, the duration of cell division has a major impact on the size of the final leaf. A number of factors have been described that regulate the developmental control of the transition between cell division and cell expansion [21]. Here, we mainly discuss the key growth regulators for which relationships.

Transcription factors are regulatory molecules of gene expression that bind to either the promoter or enhancer regions of a gene and up-/downregulate its expression [22,23]. They are a complex system controlling cellular growth, differentiation, genetic responses to the environment, and organismal development and evolution [24]. Based on our results, GIF, GRF, and TCP transcription factors showed significant up-/downregulation in triploid, indicating that these transcription factors are involved in the growth and development of triploid leaves (Table 5). Studies have shown that overexpression of GIF in plants, leaves are larger and contain more cells $[25,26]$. GIF1 protein interacts with growth regulators GRF1, GRF2 and GRF5 to regulate cell division and regulate leaf growth and development. The GIF1 protein is involved in the regulation of leaf growth by interacting with members of the putative transcription factor family GROWTH-REGULATING FACTOR1 (GRF1), GRF2 and GRF5 to regulate cell proliferation $[21,26,27]$. Horiguchi study found that overexpression of GRF5, increased cell number, resulting in increased leaf area $[26,28]$. In these plants, the initial size and growth of the leaves did not change, but growth at later stages is faster, and the duration is prolonged, indicating that the GRF5 gene mainly acts in the late stage of leaf growth and development [28]. As a transcriptional coactivator of GRF proteins, GIF proteins also contribute to leaf development. In Arabidopsis leaf development, GIF is essential for cell division [27,29]. TCP (TEOSINTE BRANCHED 1/CYCLOIDEA/PCFs) is also a family of transcription factors associated with leaf development. Studies have shown that the Arabidopsis thaliana $T C P$ gene plays a role in leaf cell growth and division. AtTCP20 is involved in cell division, cell expansion and growth coordination [30,31]. In the Arabidopsis jaw-D mutant, miR319 is overexpressed, inhibiting the expression of TCP2, TCP3, TCP4, TCP10 and TCP24, and forming large and crinkled leaves [32]. AtTCP seems to have antagonistic effects on cell growth and division [33]. Ectopic expression of AtTCP3 inhibits the formation of shoot tip meristems [34]. The TCP transcription factor family TCP2, TCP3, TCP4, $T C P 14, T C P 15, T C P 20$ and TCP24 gene expression were down-regulated in tea triploid, indicating that the down-regulation of TCP gene promoted the division and growth of triploid leaf cells (Table 5). 
Besides transcription factors, other regulators can affect the duration of cell division during leaf development. Plant hormones play an important role in the growth and development of plant organs $[32,35]$. In the analysis of tea gene expression, the expression of brassinosteroid-6-oxidase, BR60X1 and receptor protein $B R / 1$ was up-regulated, while the main physiological role of $B R s$ was to promote cell elongation and division [36]. It is regulated by $B R s$ affecting the polarity extension of cells [37,38], indicating that $B R s$ may affect the growth and development of the cell structure of tea tree triploid leaves. $A V P 1$ regulates the transport of auxin, while ARF6 mediates the synthesis of auxin $[39,40]$.

Overexpression of $A V P 1$ and $A R F 6$ genes increases the number of cells and increases leaf size [26,31]. The AUXIN-REGULATED INYOLYED INORGAN SIZE (ARGOS) gene was induced by auxin expression [41]. The $A R G O S$ gene plays a role in the positive regulation of cell division and expansion of the leaf. Overexpression of $A R G O S$ gene in Arabidopsis promoted plant leaf enlargement [41,42], while loss of $A R G O S$ gene function causes leaf size to decrease [41]. In maize, overexpression of the Zea mays ARGOS1 (ZAR1) enhances leaf, stalk and ear size, and grain yield by an increased cell number and promotes drought-stress tolerance [43].

Genes that regulate the cell cycle can affect organ morphological size. Cell division is controlled by cyclin-dependent kinases ( $C D K S$ ). The cyclin-dependent kinases $(C D K s)$ that promote chromosome duplication in $\mathrm{S}$ phase and segregation at mitosis require binding of cyclin and phosphorylation on the activation segment (T-loop) by a CDK-activating kinase (CAK) for full activity [44]. The cyclin-dependent kinase $C D K 1$ gene is up-regulated more than 6-fold compared to diploids (Table 4). The CDK1 gene plays a key role in controlling the eukaryotic cell cycle by regulating centrosome circulation and mitosis initiation; Both $C d k 1$ and -2 require cyclin-binding and T-loop phosphorylation for full activity. The only known $C D K$-activating kinase $(C A K)$ in metazoans is $C d k 7$, which is also part of the transcription machinery.

\section{Molecular analysis of the difference in stomatal formation between diploid and triploid leaves}

The stomata in the epidermal cells of plant leaves serve as the main channel for $\mathrm{CO}_{2}$ and $\mathrm{H}_{2} \mathrm{O}$ to enter and exit the leaves [45]. They are generally composed of two guard cells and intermediate pores. The size of the pores and the degree of opening and closing directly determine the transpiration and photosynthesis of plants. In this study, it was found that the size of triploid stomata was significantly larger than that of diploid and the leaf palisade palisade tissue and sponge tissue cells were looser than the diploid tea leaves, and the cell gap was large (Fig. 3,4).The external carbon dioxide enters the surface of the plant leaf through the pores and passes through the cell gap to reach the surface of the mesophyll cells covered by the chloroplast. The size of the cell surface area exposed to the intercellular space is related to photosynthetic strength. Stomatal development is accompanied by leaf growth. During the development of plant leaves, the relationship between stomatal morphology and photosynthesis function is beneficial to a comprehensive understanding of the entire life process of plant leaves. In the study of the stomata of diploid and triploid tea leaves, it was found that the diploid leaves had significantly more stomatal density than the triploid, while the triploid stomata were significantly larger than the diploid (Fig. 2). The increase in the number of pores and the size of the pores in each blade plays an important role in 
the gas exchange of the leaves. The stomatal density is reduced, which is mainly due to the growth of the leaf area. The triploid stomata become larger, indicating that the leaves are more effective in absorbing $\mathrm{CO}_{2}$ and have a stronger carbon-fixing capacity. In the differential analysis of key regulatory genes in the photosynthesis of diploid and triploid tea leaves, it was found that the photosynthesis-photoreaction phase of triploid tea leaves were down-regulated, while the key regulatory genes in the dark reaction stage were up-regulated (Table S1). This indicates that the stomata size of the triploid tea leaves and the increase of the gap between the palisade tissue and the sponge tissue are more conducive to the absorption and utilization of $\mathrm{CO}_{2}$ by photosynthesis.

Plant stomata are small holes surrounded by a pair of guard cells. Stomatal development is generally regulated by a three-step transcriptional cascade of three structurally similar bHLH (Basic-helix-loop-helix) transcription factors SPCH (SPEECHLESS), MUTE and FATA [46]. In the diploid and triploid transcription results of tea, there was no difference in $S P C H$ and $F A M A$ regulatory factor gene expression, although MUTE regulatory factors were up-regulated, but not significant. This indicates that the triploid stomatal development differences are not related to the three regulatory factors.

There are many negative regulatory factors involved in stomatal development in plants [47], such as the epidermal model factor $E P F$, the leucine-rich receptor-like protein $T M M$, the subtilisin-like $S D D 1$ and the ERECTA family (ERf) of receptor-like kinases. EPF7[48] and EPF2 [49,50] have been identified as negative factors of stomatal development. A family of secreted peptide signals known as the EPIDERMAL PATTERNING FACTORs (or EPFs) are proposed to compete for a putative cell surface receptor, believed to comprise the receptor-like protein TOO MANY MOUTHS (TMM) and a putative leucine-rich repeat receptor-like protein kinase [51,52]. Evidence suggests that receptor binding activates an intracellular mitogen-activated protein kinase cascade which phosphorylates and destabilises a $b H L H$ transcription factor required, early in leaf development, for cells to enter the stomatal lineage [53]. EPF2 and EPF1 are very similar in amino acid sequence, and it can also inhibit the development of stomata, which is achieved by blocking the production of meristemoid cells. EPF2 regulates the differentiation of the protodermal cell to the MMC, whereas EPF1 regulates the direction of the spacing division that generates satellite meristemoids. EPF2 is overexpressed, plant epidermis cannot form stomata, and stomata and non-stomatal epidermis Cells are easy to concentrate together [47]. This may prove that the gene can block the development of the initial stomatal system. The Sugano [54] group studied the regulatory factors favorable for stomatal development in Arabidopsis thaliana and found that STOMAGEN and EPF1/EPF2 competed with each other, and STOMAGEN was able to bind to the TMM receptor protein, which is the only negative regulatory family but has a positive effect on stomatal development. Overexpression of the STOMAGEN gene increases the number of stomata. Conversely, inhibition of the STOMAGEN gene reduces the number of stomata. [51]. SERKS can interact with TMM in a non-liganddependent manner to form a multiprotein receptor complex and negatively regulate stomatal development through signal transduction.

In the negative regulatory family, STOMATAL DENSITY AND DISTRIBUTION 1 (SDD1) is negatively regulated by stomatal development independent of other signaling pathways $[55,56]$. The SDD1 mutant 
increases stomatal density and forms stomatal clusters [57]. SDD1 is believed to proteolytically process certain negative signaling factors, such as EPF1 and EPF2. However, overexpression of each gene of EPF1 and EPF2 in the sdd1 background reduced stomatal densities as in wild-type plants, suggesting that function of these signaling peptides is independent of $S D D 1$ [47-49]. It is possible that negative signaling receptors (TMM and ERf) are modulated by SDD1[47]. The SDD1 gene was significantly upregulated in triploid tea leaves (Table 3). This indicates that SDD1 negatively regulates the stomatal development of the leaves of triploid tea, which reduces the stomatal density of the leaves of triploid (Fig.2).

We currently know little about how environmental factors, such as $\mathrm{CO}_{2}$ and light, regulate stomatal but as the transpiration rate of mature leaves correlates with stomatal in developing leaves. The only gene products known to modulate stomatal development in response to elevated $\mathrm{CO}_{2}$ are the carbonic anhydrases [58], and the HIGH CARBON DIOXIDE $(H I C)$ protein believed to be involved in biosynthesis of the epicuticular waxes [59-61]. The HIC gene is a factor that negatively regulates stomatal development in the sense of $\mathrm{CO}_{2}$ concentration changes in Arabidopsis. For example, when the concentration of $\mathrm{CO}_{2}$ is increased, the leaf stomatal density of wild-type plants is decreased, while the leaf stomatal density of hic-deficient mutants is significantly increased. This indicates that the HIC gene is responsible for regulating the number of stomata in a high concentration of $\mathrm{CO}_{2}$ environment.

In summary, plant stomatal development is closely regulated at multiple levels by a large number of genes as well as self-development programs and environmental signals.

\section{Conclusions}

In this study, we examined the morphological characteristics of diploid and triploid tea leaves and analyzed the molecular mechanisms underlying these differences by transcriptome analysis. A potential connection was observed between gene expression and morphology variation in diploid and triploid tea leaves. The triploid tea leaves and stomatal size is bigger than diploid. From the analysis of blade microstructure, we found that the xylem cells in the veins of the leaves of triploid tea trees are larger than diploids, and the number of xylem cells is more. Comparative transcriptome analyses demonstrated that the genes involved in cell division and expansion were more highly expressed in triploid than diploid, especially key enzymes and transcription factor that function at branch points in cell formation pathway, which might explain the biosynthesis of morphological characteristics differences in tea leaves. The transcriptome data obtained in this study will improve our understanding of the molecular mechanisms of tea leaf and stomatal development and provide the basis for molecular breeding of high quality and yield tea varieties.

\section{Methods}

\section{Plant materials and growth conditions}


Diploid tea tree: 'QianMei 419' (Guizhou Institute of Agricultural Sciences, Guizhou Academy of Agricultural Sciences - Tea Garden, Tea Lake Institute, Meitan County).

Triploid tea tree: 'QianFu No. 4' (Clonal variety 'QianMei 419' seeds mutated by Co 60-y ray. Guizhou Academy of Agricultural Sciences Tea Institute - Tea Lake Institute, Meitan County).

The annual shoots of diploid and triploid tea trees under field growth conditions were used as experimental materials.

\section{RNA Extraction}

Total RNA from tea tree diploid and triploid annual shoot leaves was extracted and purified using an RNeasy mini kit (Qiagen, Valencia, CA, USA) according to the manufacturer's instructions. RNA extraction was performed using the Qiagen RNAeasy kit (Qiagen China, Shanghai, China) kit. Detailed experimental procedures were performed according to the kit instructions. Total RNA was then detected for degradation or contamination on a $1 \%$ agarose gel electrophoresis. The purity of the RNA was detected using a spectrophotometer (IMPLEN, CA, USA). RNA concentration was determined using a fluorescence spectrophotometer (Life Technologies, CA, USA). RNA integrity was detected using the RNA Nano 6000 Assay Kit (Agilent Technologies, CA, USA) of the Bioanalyzer 2100 System. The A260/A280 is between 1.8-2.0, and the $28 \mathrm{~S} / 18 \mathrm{~S}$ is between 1.6-2.0. The sample is qualified for subsequent sequencing. The construction of the libraries and RNA-Seq were performed by Shenzhen Hengchuang Gene Technology Co., Ltd. (Shenzhen, China).

After the sample extracted total RNA was treated with DNase I, eukaryotic mRNA was enriched with magnetic beads with Oligo (dT). Then, the disruption reagent was added to break the mRNA into short fragments, and the stranded cDNA was synthesized with random hexamers using the broken mRNA as a template, and then the second strand of cDNA was synthesized by adding buffer, dNTPs and DNA polymerase I, and purified by kit. After recovery, cohesive end repair, addition of base "A" at the 3 ' end and ligation of the sequencing linker, the resulting fragment was size-selected and then amplified by PCR amplification. The constructed library was qualified by Agilent 2100 Bioanalyzer and ABI Step One Plus Real-Time PCR System and sequenced using the Illumina sequencing platform.

\section{De novo assembly and functional annotation}

The original sequencing sequence obtained by removing the adapter sequences, low quality sequences, and removes sequences having an $\mathrm{N}$ base ratio of more than $10 \%$. Finally, we refer to the filtered reads as clean reads and use them for transcriptome de novo assembly using trinity platform (trinityrnaseq_r20140717; http://trinityrnaseq.sourceforge.net/) without digital normalization according to the parameters of min_kmer_cov 3 and other default parameters.

The sequence obtained by trinty assembly is called a transcript. Then use Tgicl (v2.1) to de-redundant and further splicing to get the final unigene. Unigene, which is redundant and spliced by tgicl, is divided into two parts. Part of it is the clusters, which contain several unigenes with high similarity (greater than 
70\%) (starting with CL, followed by the number of the gene family). The rest are singletons (starting with unigene), representing a single unigene. These unigenes were annotated using the BLASTx alignment (Evalue $\leq 10^{-5}$ ) to the following databases: National Centre for Biotechnology Information (NCBI) NonRedundant database and Nucleotide Collection (Nr/Nt), Swiss-Prot, Gene Ontology(GO), Kyoto Encyclopedia of Genes and Genomes (KEGG), and the Clusters of Orthologous Groups of proteins (COG), and based on the NR annotation results, unigene performs GO function annotation through Blast2GO ( v2.5.0).

\section{GO and KEGG pathway enrichment analyses for differentially expressed unigenes}

After obtaining the GO annotation of each unigene, the WEGO software is used to perform GO function classification statistics for all unigenes, and the gene function distribution characteristics of the species are macroscopically recognized. GO and KEGG pathway enrichment analyses for the differentially expressed unigenes were then carried out. The obtained GO annotation was enriched and refined using top Go package (v2.16.0). The biologically complex behavior of the gene can be further studied by KEGG, and the Pathway annotation of unigene is obtained from the KEGG annotation information. The read counts was normalized by calculating number of reads per kilobase per million (RPKM) for each transcript in individual tissue, and the relative expression amount of the gene was calculated using $\log _{2}$ (YH29/WH10). A P-value cut-off of $\leq 0.05$ along with at least two-fold change was used to identify significant differential expression of the transcripts.

\section{Gene validation and expression analysis}

For the purpose of gene validation and expression analysis, all the DEGs related to Leaf growth related gene were subjected to quantitative real-time PCR (qRT-PCR). qRT-PCR was performed using a7500 Fast Quantitative Real-Time PCR instrument (Applied Biosystems, Waltham, Massachusetts, USA) and SYBR Premix Ex Taq (TaKaRa) according to the manufacturer's instructions. The synthesized cDNA was used for analysis of transcript abundance using Quantitative Real-Time qRT-PCR and the primers shown in Supplementary Table S2. Relative levels of transcripts were determined by normalizing expression against actin transcript levels. Experiments were replicated three times.

\section{Statistical analysis}

All data were expressed as mean \pm standard error. For qRT-PCR, three biological replicates were assessed. Microsoft Excel and GraphPad Prism 5.0 software were used for data analysis. One-way ANOVA with Duncan's multiple range test was used for post hoc comparison of multiple variables. A significant difference relative to the control was recognized at $* \mathrm{P}<0.05$ or $* \star P<0.01$.

\section{Abbreviations}

cDNA: Complementary DNA ; DNA: Deoxyribo nucleic acid; FPKM: Fragments per kilobase of transcript per million mapped reads; NCBI: National Center for Biotechnology Information; qRT-PCR: Quantitative 
real-time polymerase chain; RNA: Ribo nucleic acid; NR: Non redundant; NT: Non Taxonomy; COG: Cluster of orthologous group; GO: Gene Ontology; KEGG: Kyoto Encyclopedia of Genes and Genomes; BP :biological process; CC :cellular component; MF: molecular function ; RIN :RNA integrity number ; SDD1: Stomatal density and distribution 1; SERK: somatic embryogenesis receptor kinase; EPF: EPIDERMAL PATTERNING FACTORs; TMM: TOO MANY MOUTHS; bHLH: Basic-helix-loop-helix; SPCH: SPEECHLESS; FAMA: bHLH family transcription factor ;MUTE: bHLH family transcription factor; COP: Constitutive Photomorphogenesis ; HIC: HIGH CARBON DIOXIDE; PS 『:Photosystem I; PS «:photosystem II ; ATPase; PPC :phosphoenolpyruvate carboxylase; MDH1:malate dehydrogenase; RPB2: DNA-directed RNA polymerases I; TFIIA1: transcription initiation factor ; CDK: Cyclin-dependent kinase; CAK:CDK-activated kinase ; BUB1:serine/threonine kinase ; GIF: GRF1-interacting factor 1; GRF: GROWTH-REGULATING FACTOR1; TCP :TEOSINTE BRANCHED 1; BR60X1:brassinosteroid-6-oxidase; BRI1: BRassinosteroid Insensitive 1;ARF: auxin response factor; ARGOS: AUXIN-REGULATED INYOLYED INORGAN SIZE

\section{Declarations}

\section{Ethics approval and consent to participate}

Not applicable.

\section{Consent for publication}

Not applicable.

\section{Availability of data and material}

The datasets analyzed during the current study are available from the corresponding author on reasonable request. All data generated or analyzed during this study are included in this published article [and its Additional files].

\section{Competing interests}

The authors declare that they have no competing interests.

\section{Funding}

This work was funded by National natural science foundation (No.31160149) and by the major projects of national new varieties of genetically modified organisms (No.2014ZX08010-003-2016ZX08010-003). Long-Chain Polyunsaturated Fatty Acids Produced by Transgenic Rapeseed (Qianke Hehe LH Zi [2014] 7680), Department of Science and Technology of Guizhou Province, Guizhou University Joint Fund Project 2014, September 2014-September 2016.

\section{Authors' contributions}


YQ, LTL and DGZ conceived and designed the research. YQ and LTL conducted the experiments. YQ and $X Z Y$ contributed analytical tools and analyzed data. YQ wrote the manuscript. All authors read and approved the manuscript.

\section{Acknowledgements}

We appreciate Xinzhuan Yao, Degang Zhao for their technical support and initial data analysis.

\section{References}

[1] Rieseberg LH, Willis J H: Plant speciation. Science, 2007, 317(5840):910-914.

10.1126/science.1137729

[2] Otto S P: The Evolutionary Consequences of Polyploidy[J]. Cell, 2007, 131(3):0-462.

10.1016/j.cell.2007.10.022

[3] Meyers LA, Levin DA: On the abundance of polyploids in flowering plants.[J]. Evolution, 2010, 60(6):1198-1206. 10.1111/j.0014-3820.2006.tb01198.x

[4] Randolph, LF:Some Effects of High Temperature on Polyploidy and Other Variations in Maize. Proceedings of the National Academy of Sciences, 1932, 18(3):222-229.

10.1073/pnas.18.3.222

[5] Tel-Zur N: Chromosome Doubling in Vine Cacti Hybrids. Journal of Heredity, 2003, 94(4):329-333.

10.1093/jhered/esg064

[6] Cohen-Fix, Orna: Cell biology: Import and nuclear size. Nature, 2010, 468(7323):513-

516.10.1038/468513a

[7] Huber MD, Gerace L: The size-wise nucleus: nuclear volume control in eukaryotes. The Journal of Cell Biology, 2007, 179(4):583-584.10.1083/jcb.200710156

[8] Melaragno JE, Coleman MAW: Relationship between Endopolyploidy and Cell Size in Epidermal Tissue of Arabidopsis. The Plant Cell, 1993, 5(11):1661-1668.10.2307/3869747

[9] Olmo E: Nucleotype and cell size in vertebrates: a review. Basic and applied histochemistry, 1983, 27(4):227-256.10.1679/aohc.46.713

[10] Levin, Donald A: Polyploidy and Novelty in Flowering Plants. The American Naturalist, 1983, 122(1):1$25.10 .1086 / 284115$

[11] Warner DA, Edwards GE: Effects of polyploidy on photosynthesis[J]. Photosynthesis Research, 1993, 35(2):135-147.10.1007/BF00014744

Page 15/30 
[12] Tal M. Physiology of polyploids. Basic Life Sciences, 1979, 13:61.10.1007/978-1-4613-3069-1_4

[13] Well EV, Fossey A: A comparative investigation of seed germination, metabolism and seedling growth between two polyploid Triticum species. Euphytica, 1998, 101(1):83-89.

10.1023/a:1018320230154

[14] Hu BQ: Research on Molecular Mechanism of Triploid Vigor in Populus euramericana. Nankai University, 2013.

[15] McClintock B: The significance of responses of the genome to challenge. Science, 1984, 226(4676):792-801.10.1126/science.15739260

[16] Kashkush K, Feldman M, Levy A A: Transcriptional activation of retrotransposons alters the expression of adjacent genes in wheat. Nature Genetics, 2003, 33(1):102-106.10.1038/ng1063

[17] Cohen-Fix O: Import and nuclear size. Nature, 2011, 468(7323):513. 10.1038/468513a

[18] Huber MD, Gerace L: The size-wise nucleus: nuclear volume control in eukaryotes. The Journal of Cell Biology, 2007, 179(4):583-584. 10.1083/jcb.200710156

[19] Zhu Z, Lin H, Kang X: STUDIES ON ALLOTRIPLOID BREEDING OF POPULUS TOMENTOSA B301 CLONES. Scientia Silvae Sinicae, 1995, 31(6):499-505.

[20] Korner C, Pelaez MRS, John P: Why Are Bonsai Plants Small? A Consideration of Cell Size. Functional Plant Biology, 1989, 16(5):443-448.10.1071/pp9890443

[21] Gonzalez N , Vanhaeren H , Dirk Inzé: Leaf size control: complex coordination of cell division and expansion. Trends in Plant Science, 2012, 17(6):0-0. 10.1016/j.tplants.2012.02.003

[22] Jiang Y, Zeng B, Zhao H, Zhang M, Xie S, Lai J: Genome-wide Transcription Factor Gene Prediction and their Expressional Tissue-Specificities in Maize. Journal of Integrative Plant Biology, 2012, 54(9):616$-630.10 .1111 / \mathrm{j} .1744-7909.2012 .01149 . x$

[23] Tombuloglu H, Kekec G, Mehmet Serdal Sakcali....: Transcriptome-wide identification of r2r3-myb transcription factors in barley with their boron responsive expression analysis. MGG Molecular Genetics and Genomics.2013.288(3-4), 141-155. 10.1007/s00438-013-0740-1

[24] Postnikova OA, Shao J, Nemchinov LG: In silico identification of transcription factors inMedicago sativausing available transcriptomic resources. Molecular Genetics and Genomics, 2014, 289(3):457468.10.1007/s00438-014-0823-7

[25] Lee BH, Ko JH, Lee S, Lee Y, Pak JH, Kim JH: The Arabidopsis GRF-INTERACTING FACTOR Gene Family Performs an Overlapping Function in Determining Organ Size as Well as Multiple Developmental Properties. PLANT PHYSIOLOGY, 2009, 151(2):655-668.10.1104/pp.109.141838 
[26] Horiguchi G, Kim GT, Tsukaya H: The transcription factor AtGRF5 and the transcription coactivator AN3 regulate cell proliferation in leaf primordia of. The Plant Journal, 2005, 43(1):68-78.10.1111/j.1365313X.2005.02429.x

[27] Kim JH, Kende H: A transcriptional coactivator, AtGIF1, is involved in regulating leaf growth and morphology in Arabidopsis. Proceedings of the National Academy of Sciences, 2004, 101(36):1337413379.

[28] Gonzalez N, De Bodt S, Sulpice R, Jikumaru Y, Chae E, Dhondt S, Gonzalez N, De Bodt S, Sulpice R: Increased Leaf Size: Different Means to an End. PLANT PHYSIOLOGY, 2010, 153(3):12611279.10.1104/pp.110.156018

[29] Debernardi JM, Mecchia MA, Vercruyssen L, Smaczniak C, Kaufmann K, Inze D: Post-transcriptional control of $\backslash \mathrm{r}, G R A \mathrm{r}$, transcription factors by microRNA miR396 and GIF co-activator affects leaf size and longevity. The Plant Journal, 2014, 79(3):413-426.10.1111/tpj.12567

[30] Christine Hervé, Dabos P, Bardet C, Jauneau, A, Auriac, MC, Agnés Ramboer: In vivo Interference with AtTCP20 Function Induces Severe Plant Growth Alterations and Deregulates the Expression of Many Genes Important for Development[J]. Plant Physiology, 2009, 149(3):1462-1477.10.2307/40537729

[31] Li C, Potuschak T, Colon-Carmona A: Arabidopsis TCP20 links regulation of growth and cell division control pathways. Proceedings of the National Academy of Sciences, 2005, 102(36):12978-

12983.10.1073/pnas.0504039102

[32] Palatnik JF, Allen E, Wu X, Schommer C, Schwab R, and Carrington JC: Control of leaf morphogenesis by microRNAs[J]. Nature (London), 2003, 425(6955):257-263. 10.1038/nature01958

[33] Manassero NGU, Viola IL, Welchen E, Gonzalez DH: TCP transcription factors: architectures of plant form. BioMolecular Concepts, 2013, 4(2):111-127.10.1515/bmc-2012-0051

[34] Koyama T, Furutani M, Tasaka M, Ohmetakagi M: TCP Transcription Factors Control the Morphology of Shoot Lateral Organs via Negative Regulation of the Expression of Boundary-Specific Genes in Arabidopsis. Plant Cell, 2007, 19(2):473-484.10.1105/tpc.106.044792

[35] Gonzalez N, Vanhaeren H, Dirk Inzé: Leaf size control: complex coordination of cell division and expansion. Trends in Plant Science, 2012, 17(6):0-0. 10.1016/j.tplants.2012.02.003

[36] Kemmerling B, Schwedt A, Rodriguez P, Mazzotta S, Frank M, Qamar SA: The BRI1-Associated Kinase 1, BAK1, Has a Brassinolide-Independent Role in Plant Cell-Death Control. Current Biology, 2007, 17(13):1116-112210. 1016/j.cub.2007.05.046

[37] Ohnishi T, Godza B , Watanabe B, Fujioka S, Hategan L, Ide K: CYP90A1/CPD, a Brassinosteroid Biosynthetic Cytochrome P450 of Arabidopsis, Catalyzes C-3 Oxidation[J]. Journal of Biological Chemistry, 2012, 287(37):31551-31560. 10.1074/jbc.m112.392720 
[38] Polko JK, Pierik R, Van Zanten M, Tarkowská, Danuše, Strnad M, Voesenek LACJ: Ethylene promotes hyponastic growth through interaction with ROTUNDIFOLIA3/CYP90C1 in Arabidopsis. Journal of Experimental Botany, 2013, 64(2):613-624. 10.1093/jxb/ers356

[39] Ulmasov T, Guilfoyle HTJ: Activation and Repression of Transcription by Auxin-Response Factors. Proceedings of the National Academy of Sciences of the United States of America, 1999, 96(10):5844$5849.10 .2307 / 48205$

[40] Okushima Y, Mitina I, Quach, HL, Theologis A: AUXIN RESPONSE FACTOR 2 (ARF2): a pleiotropic developmental regulator. Plant Journal, 2005, 43(1):29-46.10.1111/j.1365-313x.2005.02426.x

[41] Hu Y, Xie AQ, Chuab NH: The Arabidopsis Auxin-Inducible Gene ARGOS Controls Lateral Organ Size. The Plant Cell, 2003, 15(9):1951-1961.10.1105/tpc.013557

[42] Wang B, Zhou X, Xu F, Gao J: Genome-wide Transcription Factor Gene Prediction and their Expressional Tissue-Specificities in Maize. Journal of Integrative Plant Biology, 2012, 54(9):616-$-630.10 .1007 / \mathrm{s} 11248-009-9324-6$

[43] Guo M, Rupe MA , Wei J, Winkler C, Goncalves-Butruille M, Weers BP: Maize ARGOS1 (ZAR1) transgenic alleles increase hybrid maize yield. Journal of Experimental Botany, 2014, 65(1):249$260.10 .1093 / \mathrm{jxb} / \mathrm{ert} 370$

[44] Morgan, David O: CYCLIN-DEPENDENT KINASES: Engines, Clocks, and Microprocessors. Annu Rev Cell Dev Biol, 1997, 13(1):261-291. 10.1146/annurev.cellbio.13.1.261

[45] Zhao X, Qiao X, Yuan J, Ma X, Zhang X: Nitric oxide inhibits blue light-induced stomatal opening by regulating the $K+$ influx in guard cells. Plant Science, 2012,184, 29-35. 10.1016/j.plantsci.2011.12.007

[46] Granier C, Turc O, Tardieu F: Co-Ordination of Cell Division and Tissue Expansion in Sunflower, Tobacco, and Pea Leaves: Dependence or Independence of Both Processes?. Journal of Plant Growth Regulation, 2000, 19(1):45-54. 10.1007/s003440000006

[47] Shimada T, Sugano SS, Hara-Nishimura I: Positive and negative peptide signals control stomatal density. Cellular \& Molecular Life Sciences, 2011, 68(12):2081-2088. 10.1007/s00018-011-0685-7

[48] Hara, K., Kajita, R., Torii, K. U., Bergmann, D. C., and Kakimoto, T. (2007). The secretory peptide gene epf1 enforces the stomatal one-cell-spacing rule. Genes \& Development, 21(14), 1720-1725.

DOI:10.1101/gad.1550707

[49] Hara K, Yokoo T, Kajita R, Onishi T, Yahata S, Peterson KM: Epidermal Cell Density is Autoregulated via a Secretory Peptide, EPIDERMAL PATTERNING FACTOR 2 in Arabidopsis Leaves. Plant and Cell Physiology, 2009, 50(6):1019-1031.10.1093/pcp/pcp068 
[50] Hunt L, Gray JE. The Signaling Peptide EPF2 Controls Asymmetric Cell Divisions during Stomatal Development. Current Biology, 2009, 19(10):864-869. 10.1016/j.cub.2009.03.069

[51] Bergmann DC, Sack FD: Stomatal Development. ANNUAL REVIEW OF PLANT BIOLOGY, 2007, 58(1):163-181. 10.1146/annurev.arplant.58.032806.104023

[52] Rowe MH, Bergmann DC: Complex signals for simple cells: the expanding ranks of signals and receptors guiding stomatal development. Current Opinion in Plant Biology, 2010, 13(5):548-555. 10.1016/j.pbi.2010.06.002

[53] Doheny-Adams T, Gray J E: Genetic manipulation of stomatal density influences stomatal size, plant growth and tolerance to restricted water supply across a growth carbon dioxide gradient. Philosophical Transactions of the Royal Society of London, 2012, 367(1588):547-55. 10.1098/rstb.2011.0272

[54] Sugano SS, Shimada T, Imai Y, Okawa K, Tamai A, Mori M: Stomagen positively regulates stomatal density in Arabidopsis. NATURE, 2009, 463(7278):241-244.10.1038/nature08682

[55] Schluter U: Photosynthetic performance of an Arabidopsis mutant with elevated stomatal density (sdd1-1) under different light regimes. Journal of Experimental Botany, 2003, 54(383):867-

874.10.1093/jxb/erg087

[56] Yoo CY, Pence HE, Jin JB, Miura, Gosney MJ, Hasegawa P M: The Arabidopsis GTL1 Transcription Factor Regulates Water Use Efficiency and Drought Tolerance by Modulating Stomatal Density via Transrepression of SDD1[J]. The Plant Cell, 2010, 22(12):4128-4141.10.1105/tpc.110.078691

[57] Berger D, Altmann T: A subtilisin-like serine protease involved in the regulation of stomatal density and distribution in Arabidopsis thaliana. Genes \& Development, 2000, 14(9):1119-

1131.10.1101/gad.14.9.1119

[58] Hu H, Boisson-Dernier, Aurélien, Israelsson-Nordstr?M MB, Hmer M, Xue, Ries A: Carbonic anhydrases are upstream regulators of $\mathrm{CO} 2$-controlled stomatal movements in guard cells. NATURE CELL BIOLOGY, 2009, 12(1):87-93.10.1038/ncb2009

[59] Gray JE, Holroyd GH, Lee FMVD, Bahrami AR, Hetherington AM: The HIC signalling pathway links CO2 perception to stomatal development. Nature, 2001, 408(6813):713-716.10.1038/35047071

[60] Bird SM, Gray JE: Signals from the cuticle affect epidermal cell differentiation. New Phytologist, $2003,157(1) .10 .1046 / j .1469-8137.2003 .00543 . x$

[61] Casson S, Gray JE. Influence of environmental factors on stomatal development. New Phytologist, 2008, 178(1):9-23. 0.1111/j.1469-8137.2007.02351.x

\section{Tables}


Table 1 Morphological characteristics of field grown diploid and triploid cytotypes of tea leaves

\begin{tabular}{lll}
\hline Character & Diploid(2n=30) Triploid(2n=45) \\
\hline Length of leaf(cm) & 12.83 & $15.83^{* *}$ \\
Breadth of leaf $(\mathrm{cm})$ & 5.26 & $7.43^{* *}$ \\
Leaf thickness $(\mu \mathrm{m})$ & 295.63 & $252.33^{* *}$ \\
Petiole L $(\mathrm{cm})$ & 0.70 & 0.67 \\
Petiole diameter $(\mathrm{mm}) 2.05$ & $2.31^{*}$ \\
Single leaf area $\left(\mathrm{cm}^{2}\right)$ & 54.26 & $86.71^{* *}$ \\
Dry leaf weight $(\mathrm{g})$ & 0.59 & $0.83^{* *}$ \\
\hline
\end{tabular}

Table 2 Sample Filter Statistics

\begin{tabular}{lllllll}
\hline Type & CaS419_1 & CaS419_2 & CaS419_3 & CaS4_1 & CaS4_2 & CaS4_3 \\
\hline Read Length & 150 & 150 & 150 & 150 & 150 & 150 \\
Total Raw Reads & 45512200 & 43924994 & 60461068 & 58155664 & 62062126 & 48399274 \\
Total Clean Reads & 45313502 & 43824272 & 60119848 & 58052958 & 61969762 & 48329186 \\
Total Clean Reads Ratio(\%) & 99.56 & 99.77 & 99.44 & 99.82 & 99.85 & 99.86 \\
Clean Reads GC(\%) & 44.91 & 45.03 & 44.61 & 48.82 & 47.13 & 47.62 \\
Clean Reads Q20(\%) & 96.10 & 96.37 & 96.11 & 96.58 & 96.73 & 95.77 \\
Clean Reads Q30(\%) & 91.14 & 91.55 & 91.17 & 91.87 & 92.19 & 90.36 \\
\hline
\end{tabular}

Table3 Differentially expressed genes (DEGs) related to stomatal development in diploid and triploid. 


\begin{tabular}{|c|c|c|c|c|c|}
\hline & Alias & Tea Genes & Putative function & $\begin{array}{l}\text { Fold } \\
\text { change }\end{array}$ & $\begin{array}{l}\text { P-value } \\
\end{array}$ \\
\hline \multirow{9}{*}{$\begin{array}{l}\text { Negative } \\
\text { regulatory } \\
\text { factors }\end{array}$} & SDD1 & Unigene48204_All & $\begin{array}{l}\text { Stomatal density and } \\
\text { distribution } 1\end{array}$ & 6.2 & 0.0001 \\
\hline & SDD1 & Unigene64413_All & $\begin{array}{l}\text { Stomatal density and } \\
\text { distribution } 1\end{array}$ & 4.4 & 0.002 \\
\hline & SDD1 & Unigene44141-All & $\begin{array}{l}\text { Stomatal density and } \\
\text { distribution } 1\end{array}$ & 2.6 & 0.0007 \\
\hline & $\begin{array}{l}\text { EPFL9/ } \\
\text { Stomagen }\end{array}$ & CL14931.Contig2_All & $\begin{array}{l}\text { Epidermal patterning } \\
\text { factors } 9\end{array}$ & -1.6 & 0.001 \\
\hline & $\begin{array}{l}\text { EPFL9/ } \\
\text { Stomagen }\end{array}$ & CL14931.Contig3_All & $\begin{array}{l}\text { Epidermal patterning } \\
\text { factors } 9\end{array}$ & -1.7 & 0.0002 \\
\hline & EPF1 & CL20193.Contig1_All & $\begin{array}{l}\text { Epidermal patterning } \\
\text { factors } 1\end{array}$ & -3.4 & 0.0003 \\
\hline & EPF2 & Unigene16900_All & $\begin{array}{l}\text { Epidermal patterning } \\
\text { factors } 2\end{array}$ & -3.7 & 0.00001 \\
\hline & SERK1 & Unigene17364_All & $\begin{array}{l}\text { somatic embryogenesis } \\
\text { receptor kinase family } \\
\text { RLKs }\end{array}$ & 2.3 & 0.00003 \\
\hline & SERK2 & Unigene27737_All & $\begin{array}{l}\text { SERK) family RLKs } \\
\text { somatic embryogenesis } \\
\text { receptor kinase family } \\
\text { RLKs }\end{array}$ & 3.3 & 0.0002 \\
\hline \multirow[t]{3}{*}{$\begin{array}{l}\text { signalling } \\
\text { molecules }\end{array}$} & COP1 & CL9988.Contig3_All & $\begin{array}{l}\text { Constitutive } \\
\text { Photomorphogenesis } 1\end{array}$ & -5.6 & 0.00007 \\
\hline & COP10 & CL16283.Contig2_All & $\begin{array}{l}\text { Constitutive } \\
\text { Photomorphogenesis } 10\end{array}$ & -2.6 & 0.00001 \\
\hline & HIC & CL494.Contig10_All & High Carbon Dioxide & 8.1 & 0.00001 \\
\hline \multirow{3}{*}{$\begin{array}{l}\text { bHLH } \\
\text { transcription } \\
\text { factor }\end{array}$} & MUTE & CL4078.Contig2_All & $\begin{array}{l}\text { bHLH family transcription } \\
\text { factor }\end{array}$ & 1.3 & 0.00001 \\
\hline & FAMA & Unigene32561_All & $\begin{array}{l}\text { bHLH family transcription } \\
\text { factor }\end{array}$ & -0.7 & 0.009 \\
\hline & $\mathrm{SPCH}$ & CL2555.Contig4_All & $\begin{array}{l}\text { bHLH family transcription } \\
\text { factor }\end{array}$ & -0.6 & 0.006 \\
\hline
\end{tabular}


Table 4 Differentially expressed genes involved in leaf developmental growth in diploid and triploid.

\begin{tabular}{|c|c|c|c|c|c|}
\hline & Alias & Tea Genes & Putative function & $\begin{array}{l}\text { Fold } \\
\text { change }\end{array}$ & $\begin{array}{l}\text { P- } \\
\text { value }\end{array}$ \\
\hline \multirow[t]{4}{*}{ Cell division } & CDK1 & CL7926.Contig1_All & $\begin{array}{l}\text { cyclin-dependent } \\
\text { kinase } 1\end{array}$ & 6.7 & $\begin{array}{l}9.94 \mathrm{E}- \\
07\end{array}$ \\
\hline & CDK7 & CL19785.Contig2_All & $\begin{array}{l}\text { cyclin-dependent } \\
\text { kinase } 7\end{array}$ & 1.2 & $\begin{array}{l}9.94 \mathrm{E}- \\
07\end{array}$ \\
\hline & BUB1 & CL19622.Contig1_All & $\begin{array}{l}\text { serine/threonine- } \\
\text { protein kinase }\end{array}$ & 2.2 & $\begin{array}{l}7.64 \mathrm{E}- \\
12\end{array}$ \\
\hline & CDC6 & CL9643.Contig2_All & $\begin{array}{l}\text { cell division control } \\
\text { protein } 6\end{array}$ & 5.1 & $\begin{array}{l}9.44 \mathrm{E}- \\
05\end{array}$ \\
\hline \multirow[t]{3}{*}{ Regulation of transcription } & TFIIA1 & CL11362.Contig6_All & $\begin{array}{l}\text { transcription } \\
\text { initiation factor }\end{array}$ & 2.6 & $\begin{array}{l}6.38 \mathrm{E}- \\
08\end{array}$ \\
\hline & RPABC5 & Unigene4377_All & $\begin{array}{l}\text { DNA-directed RNA } \\
\text { polymerases I }\end{array}$ & 1.3 & 0.03 \\
\hline & RPB2 & CL12803.Contig1_All & $\begin{array}{l}\text { DNA-directed RNA } \\
\text { polymerases }\end{array}$ & 2.6 & 0.01 \\
\hline \multirow[t]{14}{*}{$\begin{array}{l}\text { Plant hormone biosynthesis and } \\
\text { signal transduction }\end{array}$} & AUX1 & CL6041.Contig1_All & & 1.208807 & $\begin{array}{l}2.66 \mathrm{E}- \\
05\end{array}$ \\
\hline & ARF2 & CL1800.Contig7_All & $\begin{array}{l}\text { auxin response } \\
\text { factor } 2\end{array}$ & 1.8 & 0.0001 \\
\hline & ARF6 & CL2073.Contig8_All & $\begin{array}{l}\text { auxin response } \\
\text { factor } 6\end{array}$ & 9.9 & $\begin{array}{l}1.67 \mathrm{E}- \\
21\end{array}$ \\
\hline & ARF6 & Unigene643_All & $\begin{array}{l}\text { auxin response } \\
\text { factor } 6\end{array}$ & 4.5 & 0.0001 \\
\hline & ARF8 & CL1126.Contig2_All & $\begin{array}{l}\text { auxin response } \\
\text { factor } 8\end{array}$ & 3.6 & 0.001 \\
\hline & ARF19 & CL15534.Contig3_All & $\begin{array}{l}\text { auxin response } \\
\text { factor } 19\end{array}$ & 2.0 & $\begin{array}{l}7.32 \mathrm{E}- \\
14\end{array}$ \\
\hline & ARF19 & CL15534.Contig4_All & $\begin{array}{l}\text { auxin response } \\
\text { factor } 19\end{array}$ & 3.2 & $\begin{array}{l}6.14 \mathrm{E}- \\
10\end{array}$ \\
\hline & LAX1 & CL6041.Contig6_All & $\begin{array}{l}\text { Like AUXIN } \\
\text { RESISTANT1 }\end{array}$ & 1.5 & 0.007 \\
\hline & LAX4 & Unigene18078_All & $\begin{array}{l}\text { Like AUXIN } \\
\text { RESISTANT4 }\end{array}$ & 3.2 & 0.003 \\
\hline & BR60X1 & CL11134.Contig2_All & $\begin{array}{l}\text { Brassinosteroid -6- } \\
\text { oxidase }\end{array}$ & 1.4 & 0.001 \\
\hline & BIG & CL11767.Contig5_All & $\begin{array}{l}\text { Auxin transport } \\
\text { protein }\end{array}$ & 2.3 & $\begin{array}{l}9.17 \mathrm{E}- \\
09\end{array}$ \\
\hline & PIN3 & CL14227.Contig2_All & $\begin{array}{l}\text { Auxin efflux carrier } \\
\text { family protein }\end{array}$ & 1.45 & 0.007 \\
\hline & BRI1 & CL5770.Contig2_All & $\begin{array}{l}\text { BRassinosteroid } \\
\text { Insensitive } 1\end{array}$ & 1.962312 & $\begin{array}{l}1.78 \mathrm{E}- \\
07\end{array}$ \\
\hline & BRI1 & CL2868.Contig3_All & $\begin{array}{l}\text { BRassinosteroid } \\
\text { Insensitive } 1\end{array}$ & 3.274761 & $\begin{array}{l}2.67 \mathrm{E}- \\
06\end{array}$ \\
\hline
\end{tabular}

Table 5 Transcription factor identified in the DEGs involved in leaf developmental in diploid and triploid. 


\begin{tabular}{|c|c|c|c|c|c|}
\hline & Alias & Tea Genes & Putative function & $\begin{array}{l}\text { Fold } \\
\text { change }\end{array}$ & P-value \\
\hline \multirow{17}{*}{$\begin{array}{l}\text { Transcription } \\
\text { factor }\end{array}$} & TCP2 & Unigene6055_All & TEOSINTE & -4.5 & 0.002 \\
\hline & TCP3 & Unigene43100_All & $\begin{array}{l}\text { BRANCHED1/CYCLOIDEA/PCF } \\
\text { TEOSINTE }\end{array}$ & -2.83923 & 0.001 \\
\hline & TCP4 & Unigene26990_All & $\begin{array}{l}\text { BRANCHED1/CYCLOIDEA/PCF } \\
\text { TEOSINTE }\end{array}$ & -1.17505 & 0.08 \\
\hline & TCP7 & Unigene28095_All & $\begin{array}{l}\text { BRANCHED1/CYCLOIDEA/PCF } \\
\text { TEOSINTE }\end{array}$ & -2.46923 & $1.02 \mathrm{E}-05$ \\
\hline & TCP11 & Unigene16745_All & $\begin{array}{l}\text { BRANCHED1/CYCLOIDEA/PCF } \\
\text { TEOSINTE }\end{array}$ & -2.85517 & 2.08E-06 \\
\hline & TCP14 & Unigene11723_All & $\begin{array}{l}\text { BRANCHED1/CYCLOIDEA/PCF } \\
\text { TEOSINTE }\end{array}$ & -2.724 & 4.93E-05 \\
\hline & TCP15 & CL1762.Contig2_All & $\begin{array}{l}\text { BRANCHED1/CYCLOIDEA/PCF } \\
\text { TEOSINTE }\end{array}$ & -4.24584 & 0.004 \\
\hline & TCP15 & Unigene11723_All & $\begin{array}{l}\text { BRANCHED1/CYCLOIDEA/PCF } \\
\text { TEOSINTE }\end{array}$ & -2.724 & 4.93E-05 \\
\hline & TCP20 & Unigene45934_All & $\begin{array}{l}\text { BRANCHED1/CYCLOIDEA/PCF } \\
\text { TEOSINTE }\end{array}$ & -3.02894 & 0.05 \\
\hline & TCP20 & CL1598.Contig1_All & $\begin{array}{l}\text { BRANCHED1/CYCLOIDEA/PCF } \\
\text { TEOSINTE }\end{array}$ & -3.49031 & 0.02 \\
\hline & ТCP24 & Unigene6055_All & $\begin{array}{l}\text { BRANCHED1/CYCLOIDEA/PCF } \\
\text { TEOSINTE }\end{array}$ & -4.45414 & 0.002 \\
\hline & GRF1 & CL766.Contig8_All & $\begin{array}{l}\text { BRANCHED1/CYCLOIDEA/PCF } \\
\text { GROWTH-REGULATING FACTOR }\end{array}$ & 3.976247 & $2.05 \mathrm{E}-06$ \\
\hline & GRF5 & CL6110.Contig2_All & GROWTH-REGULATING FACTOR & 2.261885 & 0.0144514 \\
\hline & GRF7 & CL13904.Contig1_All & GROWTH-REGULATING FACTOR & 3.477404 & 0.000316 \\
\hline & GRF9 & CL13904.Contig2_All & GROWTH-REGULATING FACTOR & 3.344828 & 0.002714 \\
\hline & GIF1 & CL766.Contig8_All & GRF1-interacting factor 1 & 3.976247 & 2.05E-06 \\
\hline & ARGOS & Unigene22883_All & $\begin{array}{l}\text { AUXIN-REGULATED GENE } \\
\text { INVOLVED IN ORGAN SIZE }\end{array}$ & 2.03898 & 3.67E-05 \\
\hline
\end{tabular}

\section{Figures}




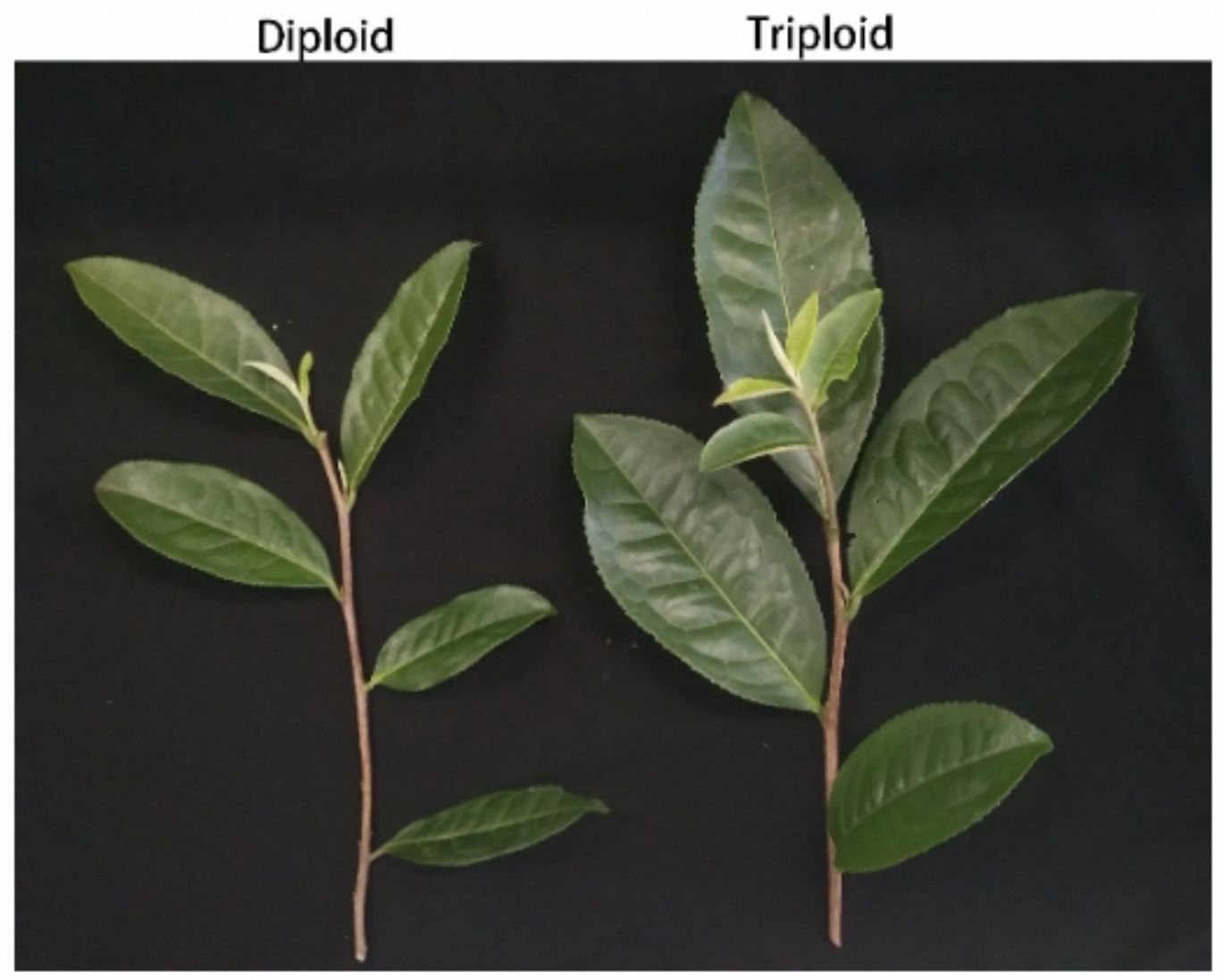

Figure 1

Morphological characteristics of diploid and triploid tea leaves. 
A

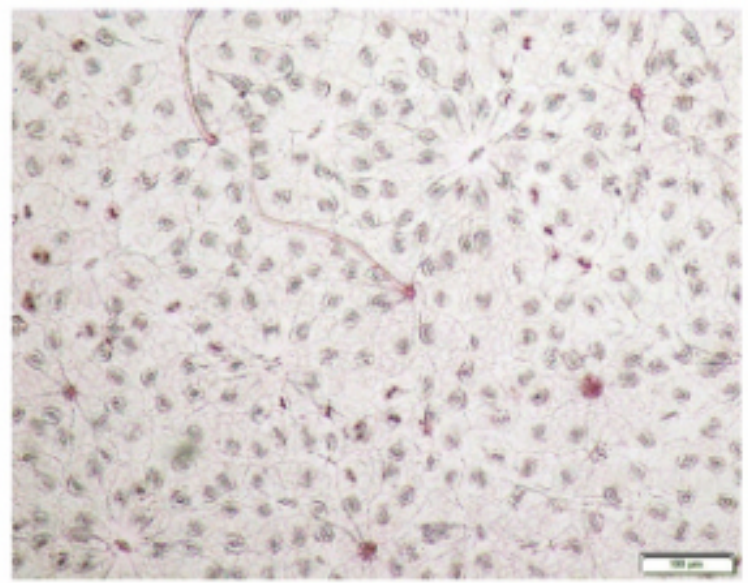

B
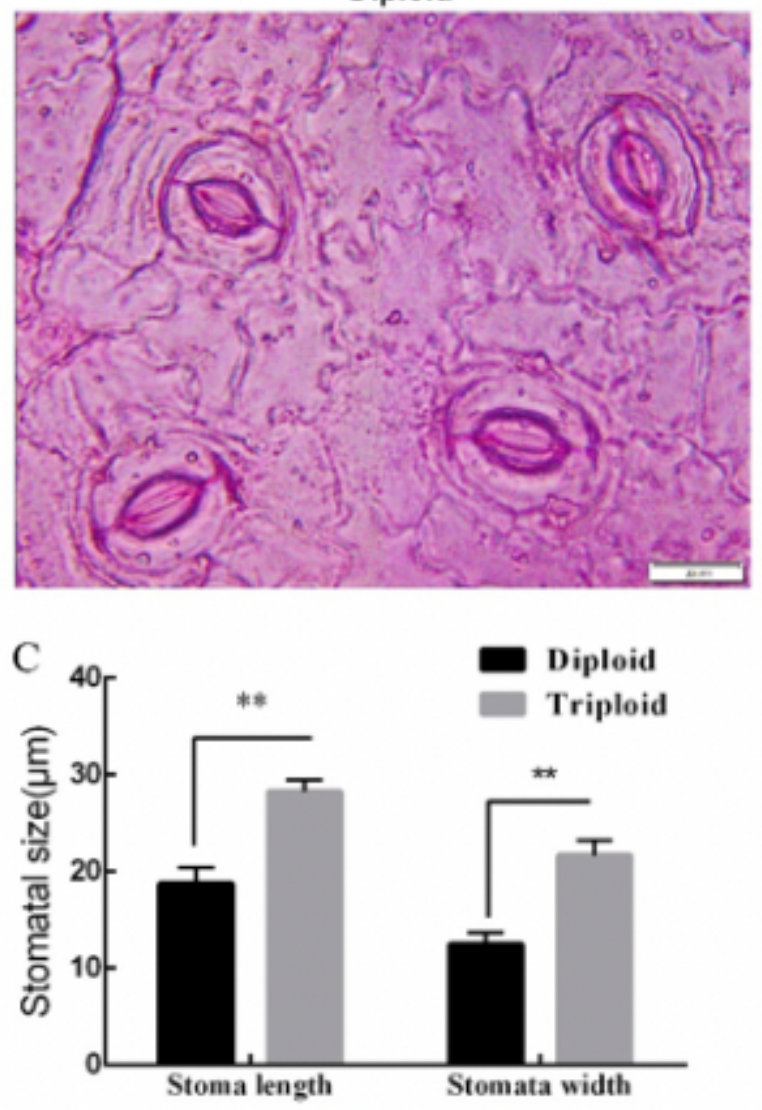

Triploid
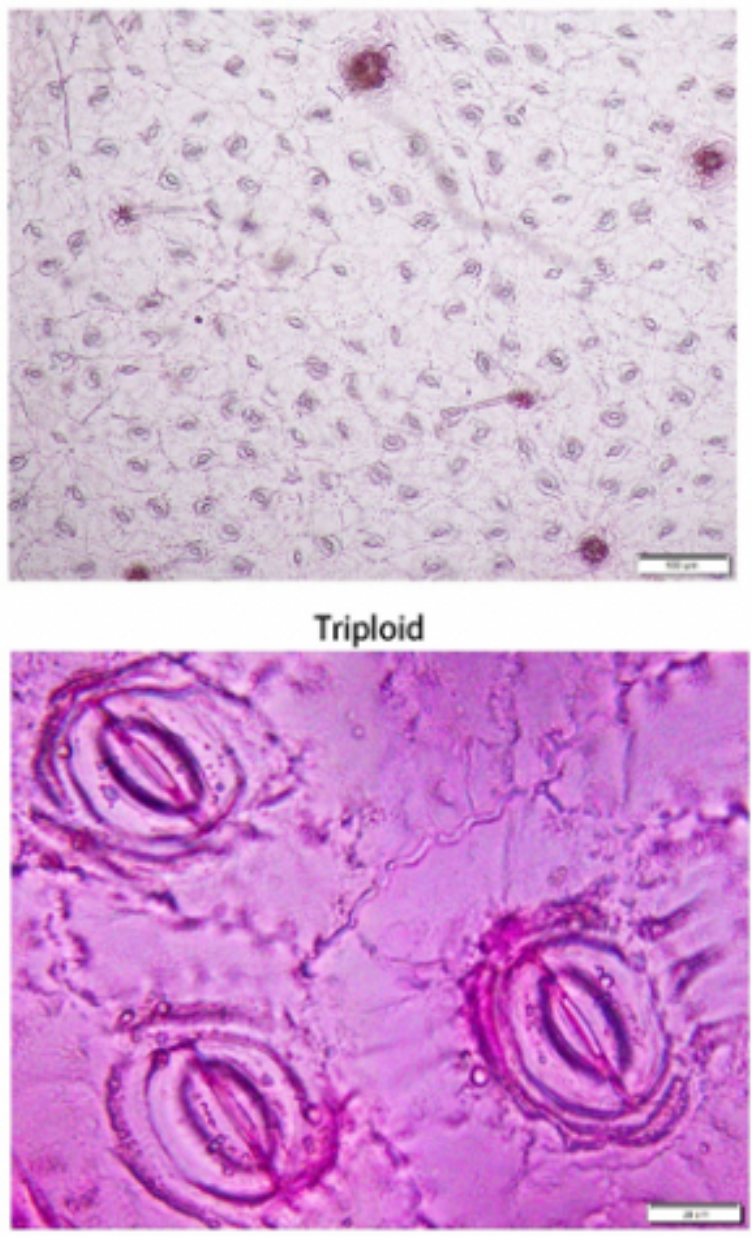

D

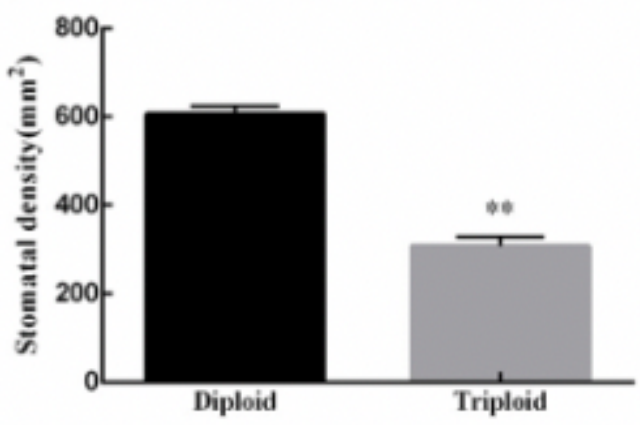

Figure 2

Number of stomata in diploid and triploid tea leaves. A: Number of diploid stomata and triploid stomata at 100X magnification; B: Number of diploid stomata and triploid stomata at 1000X magnification; C: Length and width of diploid and triploid stomatal; D: Diploid and triploid stomatal density in the same field of view. Error bars indicate SD $(n=3)$; statistical significance is indicated ${ }^{*} P<0.05, * * P<0.01$; 


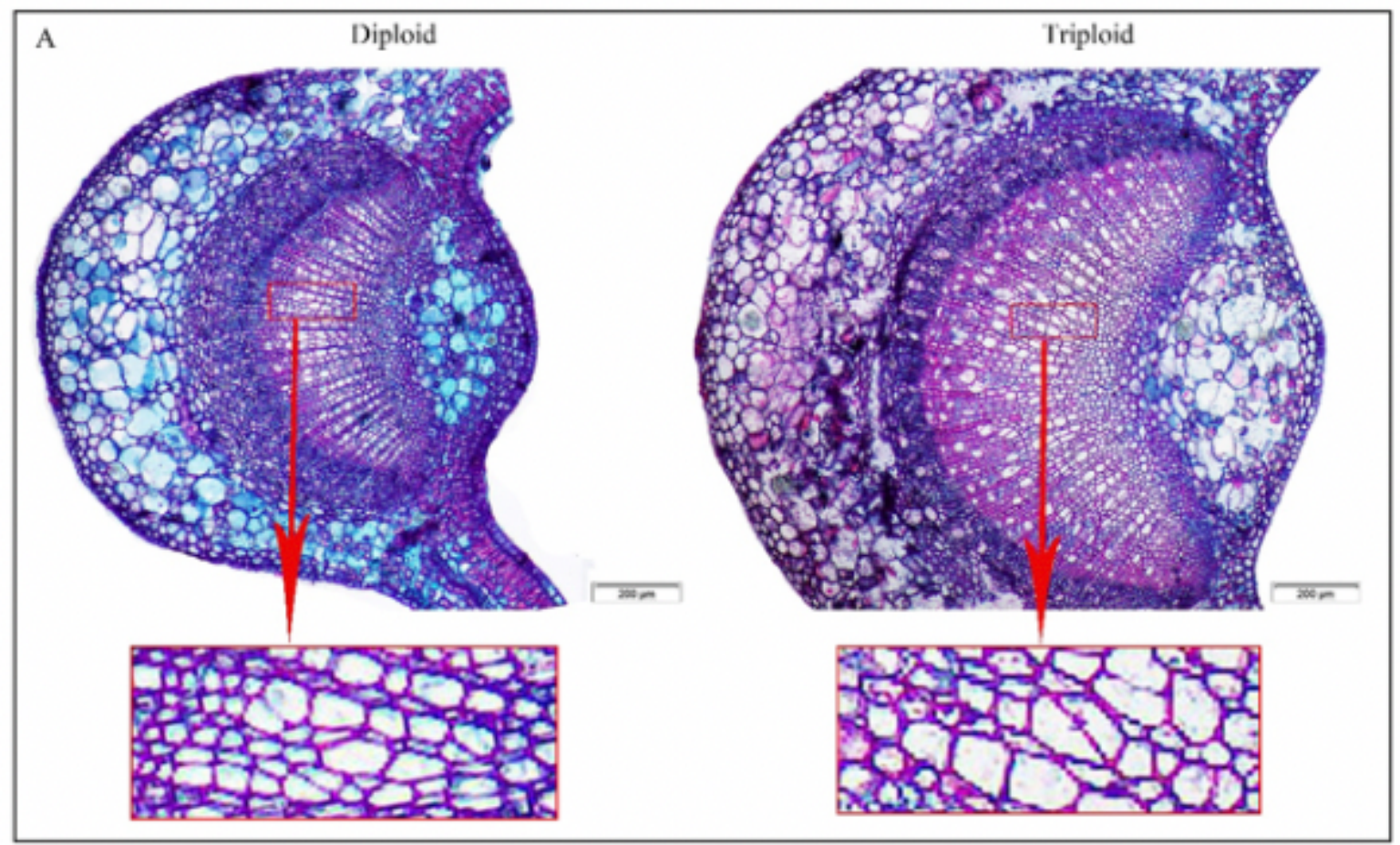

B

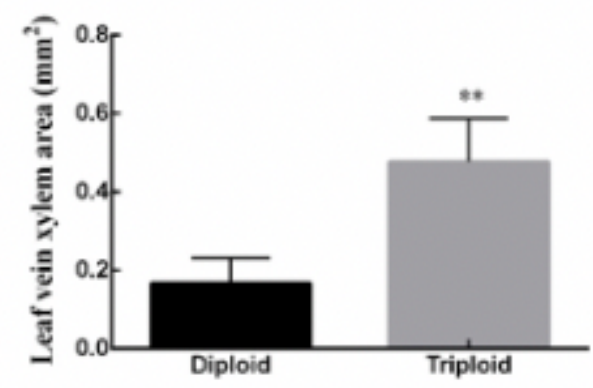

C

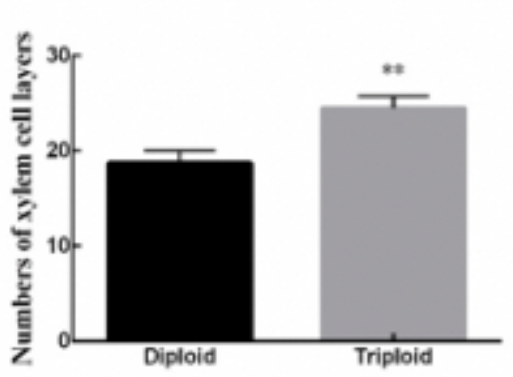

\section{Figure 3}

Transverse section of tea diploid and triploid leaf veins. A: Diploid and triploid vein xylem cross section under 50X magnification. B\&C: Were the statistical data of cross sections of diploid and triploid leaf vein xylem blades. Error bars indicate SD $(n=3)$; ** indicated significant difference at the 0.01 level compared the diploid to triploid 

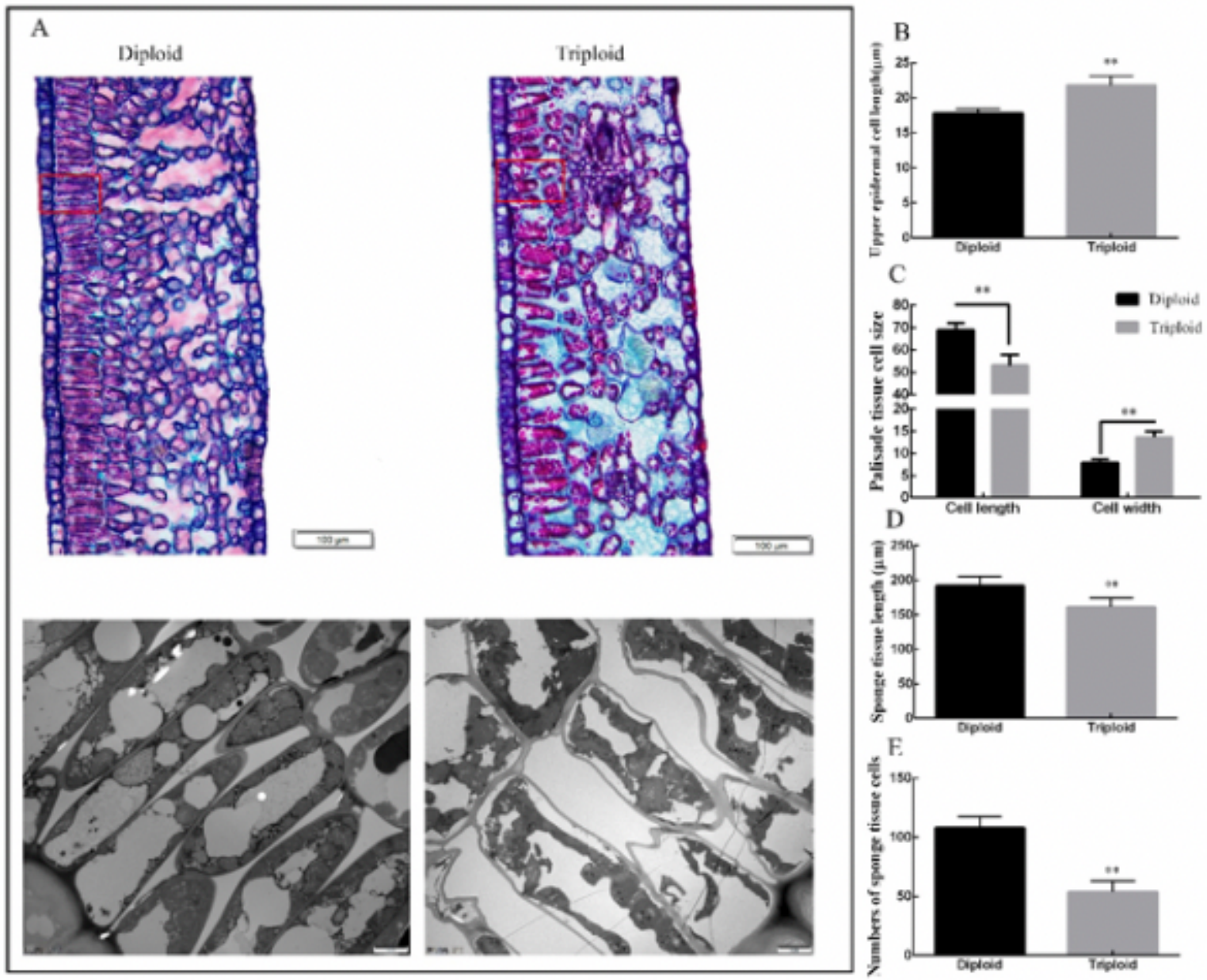

\section{Figure 4}

Transverse section of tea diploid and triploid leaf mesophyll. A: Diploid and triploid mesophyll cross section under 100X magnification. B-E: Indicated the cross sectional the length of upper epidermal cell, the size of palisade tissue cell, the number of sponge tissue cell and sponge tissue length. Error bars indicate SD $(n=3) ; * \star$ indicated significant difference at the 0.01 level compared the diploid to triploid.
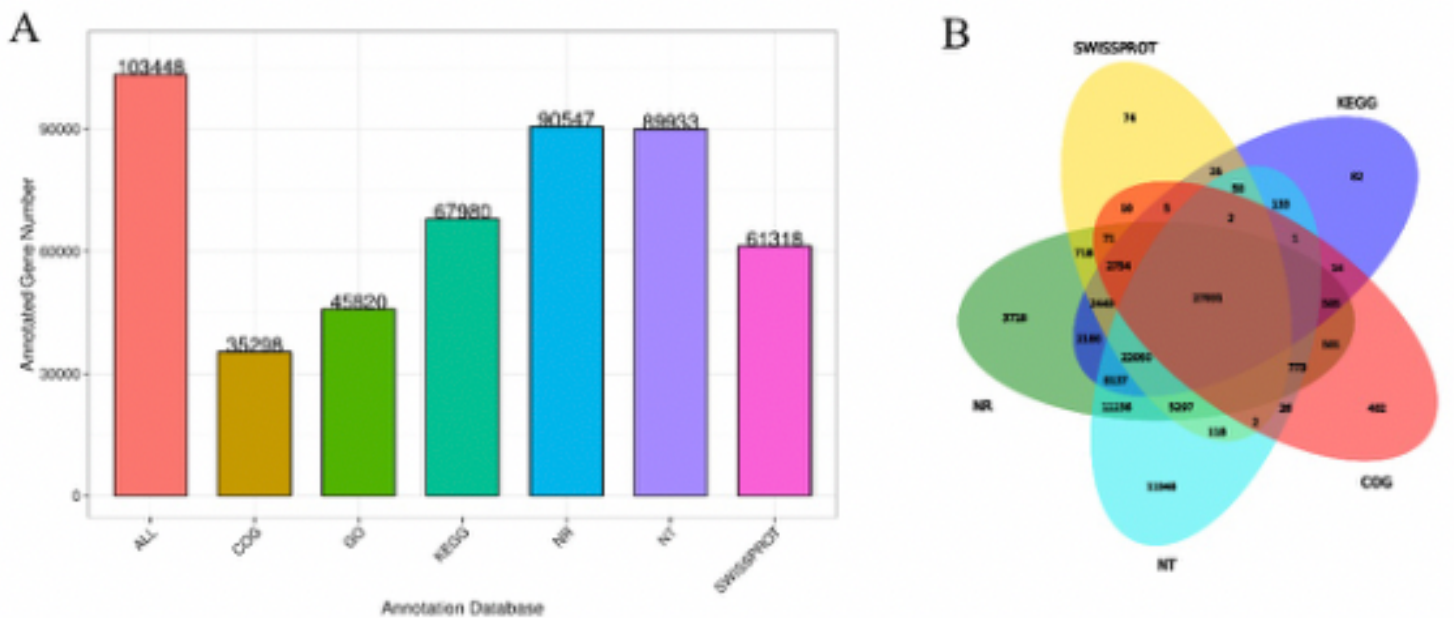
Figure 5

Unigene database statistics and functional annotations Venn diagram. A: The X-axis represents the database, where All represents the union of all the data, the Y-axis represents the number of Unigenes on the corresponding database annotation, and the number in the figure corresponds to the number of Unigenes on the annotation. B: The Venn diagram showing the number of specific genes between the two sample.

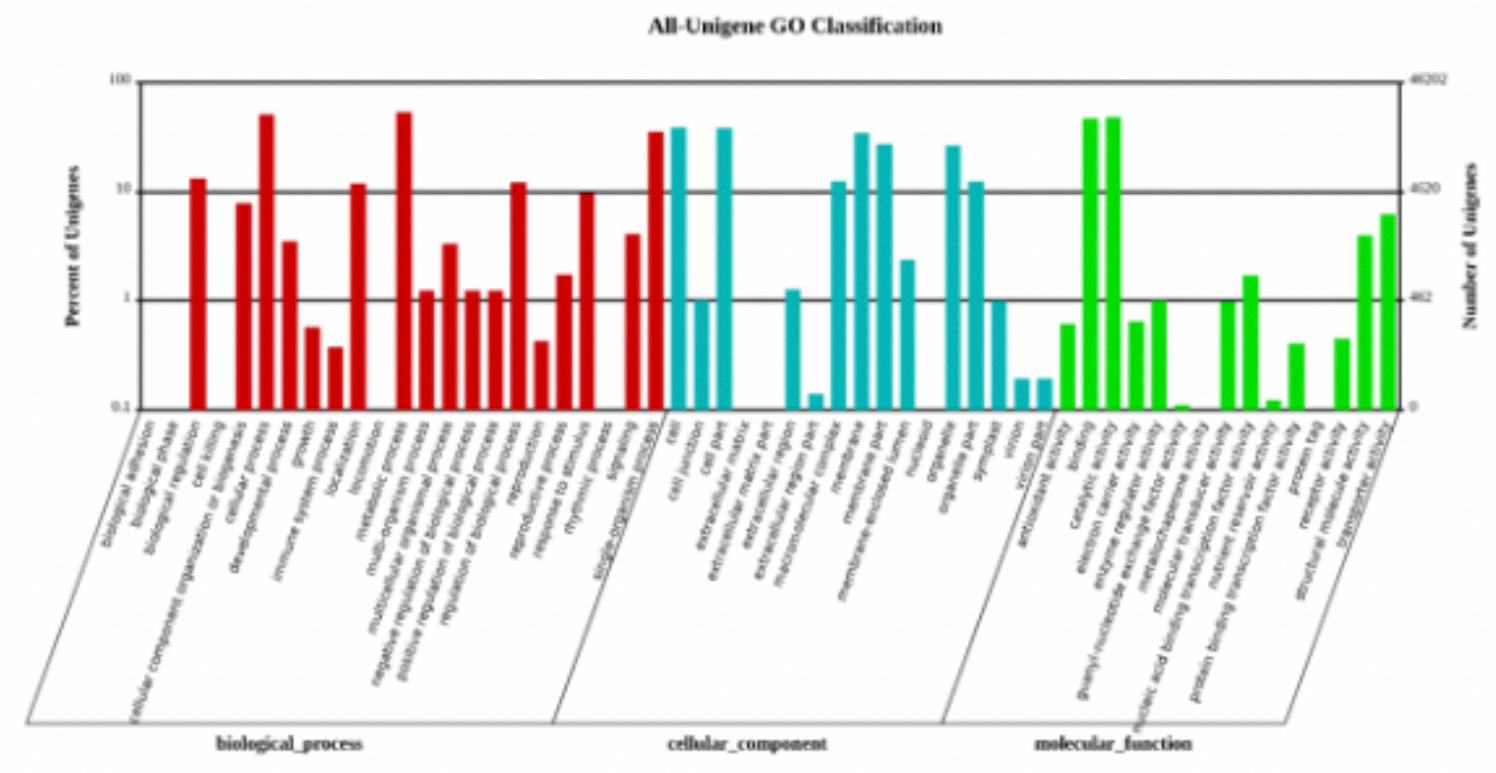

Figure 6

GO classification map. The abscissa is the GO term of the next level of the three major categories of GO, and the ordinate is the number of genes annotated to the term (including the subterm of the term). The three different classifications represent the three basic tree classifications of Go term (from left to right, biological processes, cellular components, molecular functions). 


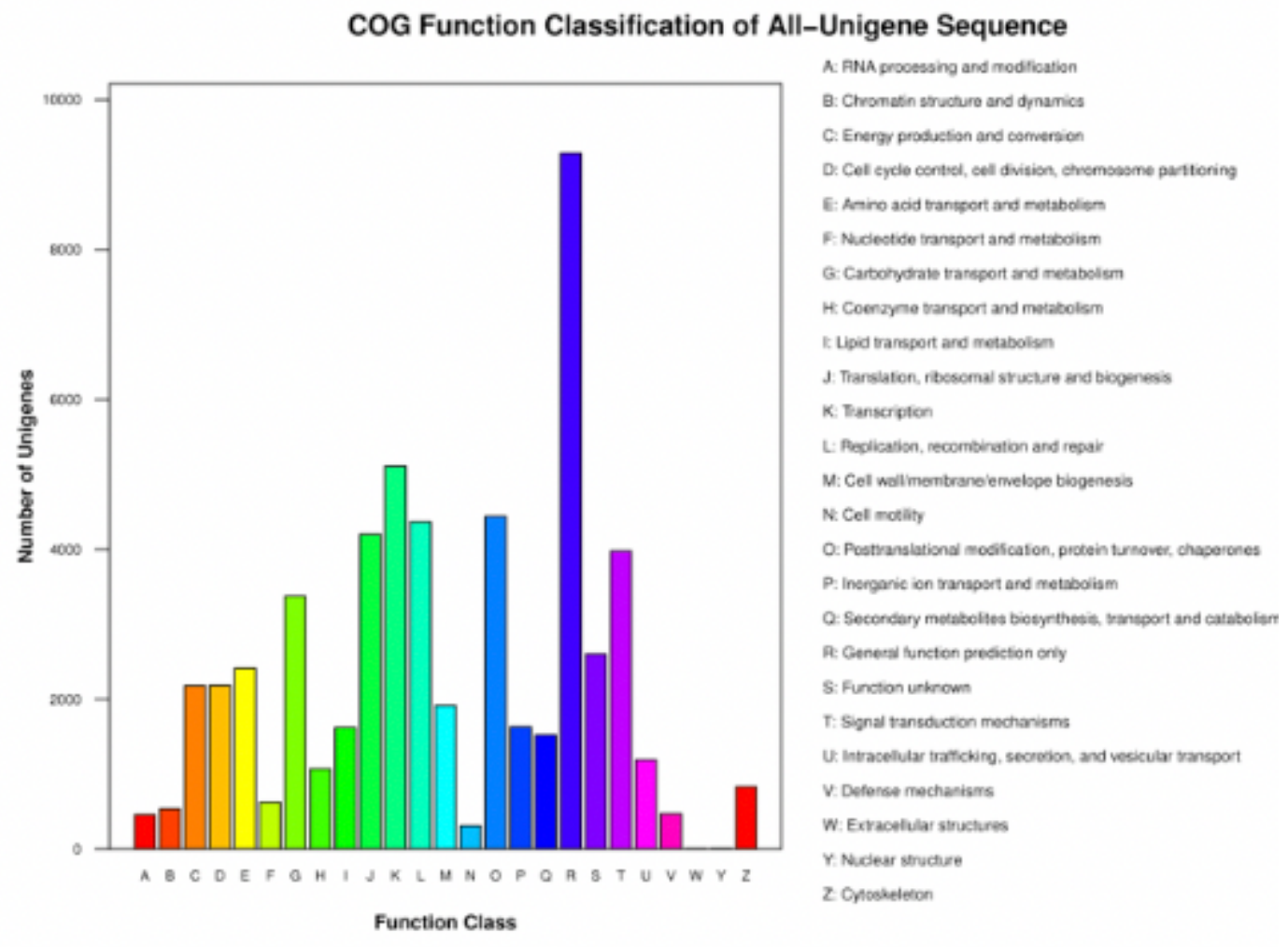

Figure 7

COG function classifications of unigenes for Clari as macrocephalus. Lefty-axis indicates the number of unigenes; letters on the $x$-axis represent different COG categories

А

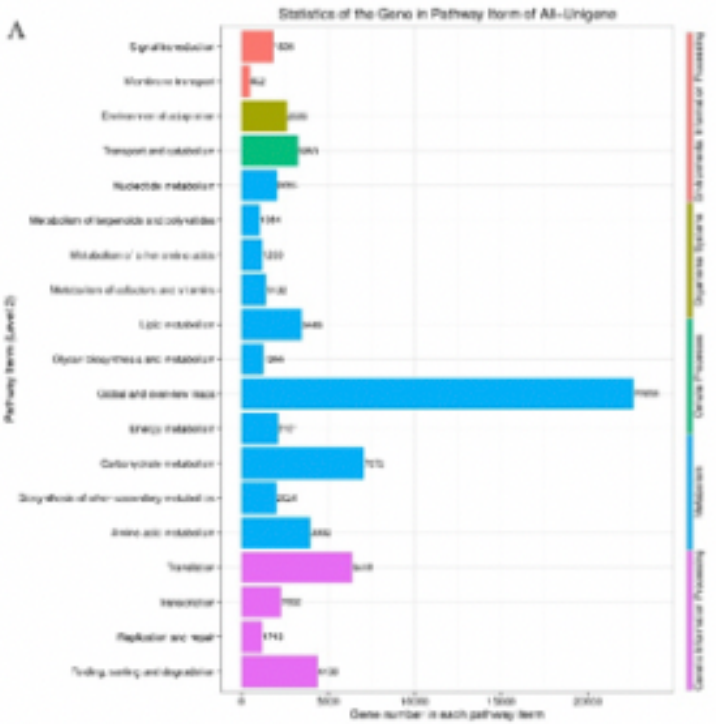

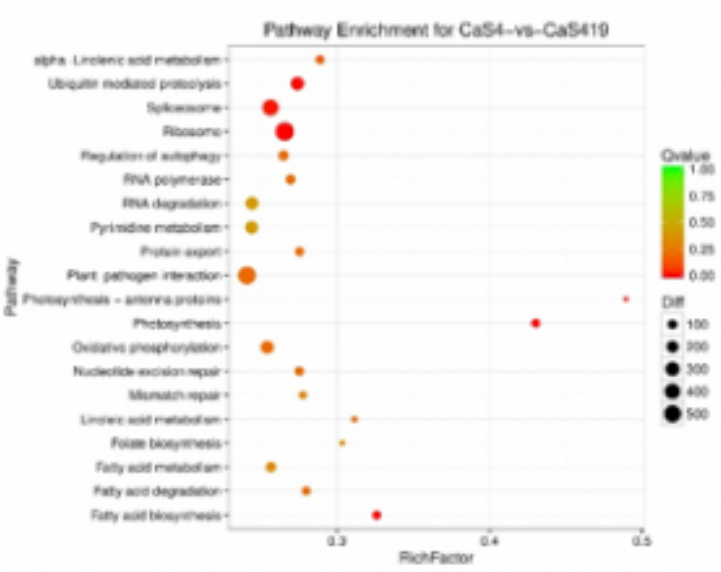

Figure 8 
Unigene KEGG annotation function distribution statistics and differential expression gene Pathway enrichment analysis

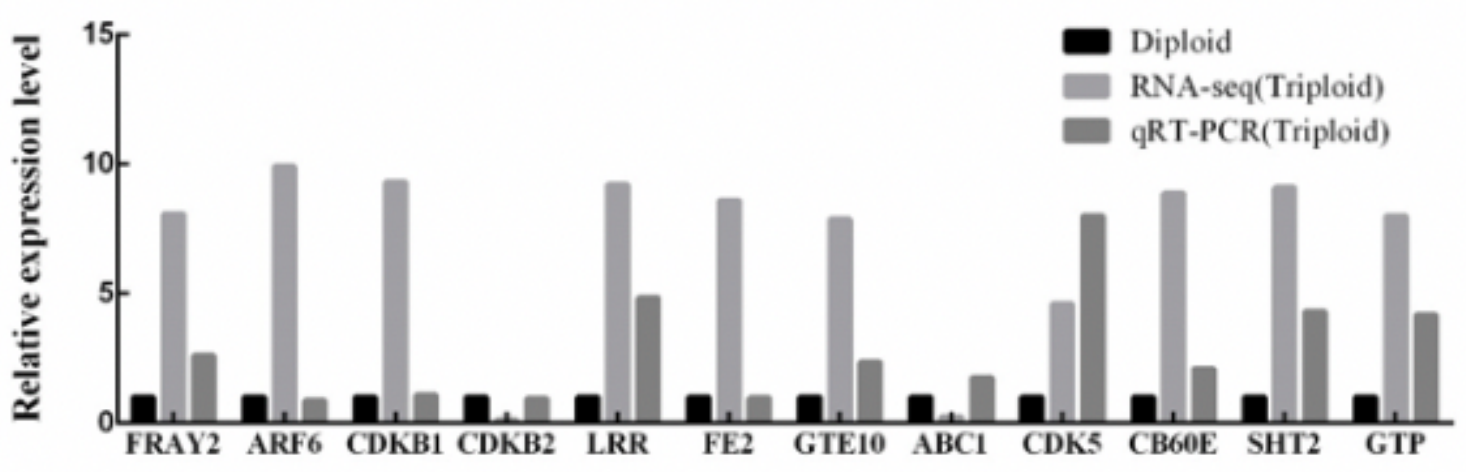

Figure 9

Expression pattern of genes related with growth and development of diploid and triploid tea leaves by qRT-PCR 